\title{
Specific $N$-glycans regulate an extracellular adhesion complex during somatosensory dendrite patterning
}

\author{
Maisha Rahman ${ }^{1,2}$, Nelson J. Ramirez-Suarez ${ }^{2 \#}$, Carlos A. Diaz-Balzac ${ }^{2, \S}$, and Hannes \\ E. Bülow ${ }^{1,2, *}$
}

Dominick P. Purpura Department of Neuroscience ${ }^{1}$ and Department of Genetics ${ }^{2}$

Albert Einstein College of Medicine

Bronx, New York 10461, USA

* corresponding author: Telephone 7184303621 , Fax 7184308778

Email: hannes.buelow@einsteinmed.org

\# present address: Institute of Science and Technology Austria, Am Campus 1, 3400 Klosterneuburg, Austria.

$\S$ present address: University of Rochester, Rochester, New York, 14627

Running title: Specific N-glycans shape dendrites

4 Figures

4 Expanded View Figures 


\begin{abstract}
$N$-glycans are molecularly diverse sugars borne by over $70 \%$ of proteins transiting the secretory pathway and have been implicated in protein folding, stability, and localization. Mutations in genes important for $N$-glycosylation result in congenital disorders of glycosylation that are often associated with intellectual disability. Here, we show that structurally distinct $N$-glycans regulate the activity of an extracellular protein complex involved in patterning of somatosensory dendrites in Caenorhabditis elegans. Specifically, aman-2/Golgi alpha-mannosidase II, a conserved key enzyme in the biosynthesis of specific $N$-glycans regulates the activity of the Menorin adhesion complex without obviously affecting protein stability and localization of its components. AMAN-2 functions cell-autonomously to ensure decoration of the neuronal transmembrane receptor DMA-1/LRR-TM with high-mannose/hybrid Nglycans. Moreover, distinct types of $N$-glycans on specific $N$-glycosylation sites regulate the DMA-1/LRR-TM receptor, which together with three other extracellular proteins forms the Menorin adhesion complex. In summary, specific $N$-glycan structures regulate dendrite patterning by coordinating the activity of an extracellular adhesion complex suggesting that the molecular diversity of $\mathrm{N}$-glycans can contribute to developmental specificity in the nervous system.
\end{abstract}

Keywords:

adhesion/alpha mannosidase II/glycosylation/dendrite/N-glycans 


\section{INTRODUCTION}

Development of a nervous system in metazoans requires the coordinated interactions of extracellular molecules to ensure correct neuronal morphogenesis, and to establish connectivity (Jan \& Jan, 2010; Dong et al, 2015; Lefebvre, 2021). Most of these extracellular proteins are glycoconjugates, i.e. carry different types of glycans attached to the protein backbone. Glycans are molecularly the most diverse molecules in nature, in part because they are not genetically encoded. Yet their structures are not random and are therefore conceptually attractive to broaden the molecular diversity and specificity of extracellular proteins and their interactions during development. For example, glycosaminoglycans, a class of glycans, have been suggested to modulate protein-protein interactions and provide information during development by way of their structural diversity (Holt \& Dickson, 2005; Bülow \& Hobert, 2006; Poulain \& Yost, 2015; Masu, 2016). Whether the structural diversity of other classes of glycans such as $\mathrm{N}$ glycans and O-glycans serve similar functions is unclear.

$N$-glycans are a structurally diverse group of glycans that fall into four classes: highmannose, hybrid, complex, and paucimannose-type $\mathrm{N}$-glycans, and are invariantly attached via an asparagine to a protein backbone (Stanley et al, 2015). Importantly, 70\% of all proteins transiting the endoplasmic reticulum are post-translationally $\mathrm{N}$ glycosylated (Apweiler et al, 1999). Therefore, the structural diversity of $N$-glycans could significantly expand the repertoire and specificity of protein interactions in the extracellular space. $\mathrm{N}$-glycans in general have been shown to be important for protein folding, stability, and localization (Stanley et al., 2015). Moreover, mutations in genes involved in $\mathrm{N}$-glycosylation in humans result in Congenital disorders of glycosylation (CDG), which are multi-syndromic and often include neurological symptoms, including intellectual disability (Freeze, 2006; Jaeken \& Peanne, 2017; Chang et al, 2018; Ng \& Freeze, 2018). Studies in vertebrates and invertebrates have shown that mutants that 
compromise $\mathrm{N}$-glycan biosynthesis or $\mathrm{N}$-glycan attachment result in defects in cell surface localization of cell adhesion molecules and axon guidance cues (Sekine et al, 2013; Medina-Cano et al, 2018; Mire et al, 2018). The question of whether and how specific classes of $\mathrm{N}$-glycans modulate extracellular pathways or complexes during nervous system development has not been explored.

Here we use PVD somatosensory dendrites, which display complex and stereotyped branching patterns in the nematode Caenorhabditis elegans (Fig.1A) (Oren-Suissa et al, 2010; Smith et al, 2010; Albeg et al, 2011) to investigate the role of different classes of $N$-glycans during development. We found that aman-2/Golgi alpha-mannosidase II, a conserved enzyme important for the synthesis of complex and paucimannose-type $\mathrm{N}$ glycans is required for PVD dendrite morphogenesis. Specifically, aman-2/Golgi alphamannosidase II ensures the correct decoration of the leucine-rich transmembrane receptor DMA-1/LRR-TM in PVD with high-mannose and paucimannose-type $N$-glycans on specific $N$-glycosylation sites. Rather than controlling trafficking or surface localization of DMA-1/LRR-TM, we provide evidence that correct N-glycosylation of DMA-1/LRR-TM is essential for the function of DMA-1/LRR-TM as part of the Menorin pathway during PVD patterning. This pathway comprises two conserved cell adhesion molecules SAX7/L1CAM and MNR-1/Menorin that function from the epidermis, and a secreted chemokine LECT-2/Chondromodulin II from muscle that together with DMA-1/LRR-TM form a high affinity cell adhesion complex (Fig.1B) (Inberg et al, 2019; Sundararajan et al, 2019). Together, our experiments suggest that distinct classes of $N$-glycans serve specific functions beyond protein folding and localization, and can contribute to developmental specificity during neuronal morphogenesis.

\section{RESULTS}


The $N$-glycosylation enzyme AMAN-2/Golgi alpha-mannosidase II is required for PVD dendrite patterning.

To identify additional factors that regulate the Menorin pathway, we performed an unbiased genetic screen for factors that modify a partial loss of function allele of the chemokine lect-2/Chondromodulin II (Diaz-Balzac et al, 2016; Zou et al, 2016). We isolated $d z 261$ as a strong enhancer of the partial loss of function lect-2 mutation in addition to other alleles in known genes of the Menorin pathway (Fig.1A,D, Fig.EV1A-C). Using a combination of mapping, sequencing and transformation rescue we identified dz261 as an allele of aman-2/Golgi alpha-mannosidase II (Fig.1C, Fig.EV1A-C), which encodes a central enzyme in the $N$-glycosylation biosynthetic pathway not previously implicated in dendrite development. The allele $d z 261$ is likely a complete loss of function mutation as it introduces an early stop codon (Fig.1C, Fig. EV1A-C). Quantifications of PVD branching patterns in aman-2(dz261) null mutants, as well as four additional nonsense/deletion alleles of aman-2, demonstrate that this Golgi alpha-mannosidase II is required for the formation of quaternary branches, but not for the formation of secondary or tertiary branches of PVD dendrites (Fig.1D,E, Fig. EV1D). These observations are reminiscent of hypomorphic alleles of dma-1/LRR-TM (Tang et al, 2019) and suggest that aman-2 may be necessary for full functionality of the Menorin pathway.

\section{AMAN-2/Golgi alpha-mannosidase II positively regulates the Menorin pathway.}

To directly test the genetic relationship between aman-2/Golgi alpha-mannosidase II and the Menorin pathway, we performed double mutant analyses. We found that the loss of aman-2/Golgi alpha-mannosidase // strongly enhances the severity of PVD branching defects in partial loss-of-function mutants of lect-2/Chondromodulin II (gk864764) and mnr-1/Menorin (dz213, Ramirez-Suarez \& Bülow, unpublished) (Fig.1A,E,F,G), both of 
which are essential components of the conserved Menorin cell adhesion complex, and act as positive regulators of PVD development (Fig.1E-G) (Dong et al, 2013; Salzberg et al, 2013; Diaz-Balzac et al., 2016; Zou et al., 2016). In contrast, loss of aman-2/Golgi alpha-mannosidase /I suppressed the self-avoidance defects of tertiary dendrites in partial loss of a function mutation of kpc-1/Furin (dz254) (Fig.1H,I, Fig. EV1C), a known negative regulator of the Menorin pathway (Schroeder et al, 2013; Salzberg et al, 2014; Dong et al, 2016). Therefore, we conclude that aman-2/Golgi alpha-mannosidase II normally functions to positively regulate the Menorin pathway to ensure correct PVD dendrite patterning.

\section{AMAN-2/Golgi alpha-mannosidase II does not serve obvious functions in}

\section{regulating transport or abundance of the DMA-1/LRR-TM.}

Mutations in $\mathrm{N}$-glycosylation are often associated with protein folding defects and trafficking blocks due to misfolding (Stanley et al., 2015) and can, for example, result in lower abundance of cell surface proteins such as cell adhesion proteins in the nervous system (Medina-Cano et al., 2018). Because protein misfolding is more likely to occur at elevated temperatures (Gasser et al, 2008; Vabulas et al, 2010), we tested whether PVD branching defects in aman-2/Golgi alpha-mannosidase /I mutations get progressively more severe with increasing temperatures. We found no significant increase in dendrite branching defects at $25^{\circ} \mathrm{C}$ compared to $15^{\circ} \mathrm{C}$ in aman-2(gk248486) mutant animals, in contrast to hypomorphic lect-2(gk864764) mutant animals (Fig. EV2A, B). Previous work showed that mutations causing a secretory block as a result of a defective unfolded protein response trap a DMA-1::GFP reporter in the cell body of PVD (Wei et al, 2015; Salzberg et al, 2017). We therefore questioned whether the loss of aman-2/Golgi alphamannosidase II can lead to defects in protein folding and trafficking, and a possible secretory block. We analyzed the amount and number of puncta of the DMA-1::GFP 
reporter in the soma, as well as in dendrite branches, and found that DMA-1::GFP fluorescence in both the soma and primary dendrites, and the number of DMA-1::GFP puncta in tertiary dendrites remained unaffected in aman-2(gk248486) mutant animals (Fig.EV2C-E). Moreover, localization or abundance of LECT-2/Chondromodulin II and SAX-7/L1CAM were also not obviously affected by loss of aman-2/Golgi alphamannosidase II (data not shown). Taken together, these findings suggest that AMAN2/Golgi alpha-mannosidase II does not primarily function to ensure protein folding, stability, or transport of factors of the Menorin pathway, but may rather regulate more specific aspects of the Menorin pathway during PVD patterning.

\section{Enzymatic activity of AMAN-2/Golgi alpha-mannosidase II is required cell-}

\section{autonomously in PVD to form higher order branches.}

The octasaccharide GnMan5Gn2 in a specific linkage configuration is the unique precursor to hybrid, complex, and paucimannose N-glycans (Fig.2A,B;Fig.3A) (Moremen, 2002; Paschinger et al, 2019). AMAN-2 is a Golgi alpha-mannosidase II, which is conserved from yeast to humans, and cleaves two specific mannose residues from GnMan5Gn2, thereby generating the substrate for formation of complex and paucimannose., N-glycans (Fig.2A,B;Fig.3A) (Moremen, 2002; Paschinger et al., 2019). To determine where AMAN-2/Golgi alpha-mannosidase II functions and whether enzymatic activity is required for its role in PVD dendrite morphogenesis, we investigated transgenic expression of a wildtype AMAN-2 cDNA under the control of heterologous promoters in PVD, muscle or epidermis for their ability to rescue aman-2 mutant defects. Expression in PVD, but not muscle or epidermis rescued the enhanced phenotypes in PVD dendrite branching of lect-2(gk864764); aman-2(gk248486) and $m n r-1(d z 213)$ aman-2(gk248486) double mutants (Fig.2C). These observations suggest 
that AMAN-2/Golgi alpha-mannosidase II functions cell-autonomously to pattern PVD dendritic arbors.

Since AMAN-2/Golgi alpha-mannosidase II canonically functions as an enzyme (Moremen, 2002; Shah et al, 2008), we next asked whether catalytic activity is required for its role in PVD dendrite branching. We approached this both genetically and pharmacologically. Prior studies showed that two highly-conserved aspartates are part of the conserved catalytic site in AMAN-2/Golgi alpha-mannosidases II (D306 and D443) and act sequentially to cleave off two mannose residues (Fig.2D) (Shah et al., 2008). We found that an AMAN-2 cDNA with both aspartates mutated, and hence likely catalytically dead, failed to rescue the defects in lect-2(gk864764); aman-2(gk248486) and mnr1(dz213) aman-2(gk248486) double mutants (Fig. 2C). To address the possibility that mutating the catalytic residues compromised the stability or structure of AMAN-2, we took advantage of swainsonine, a compound that specifically inhibits Golgi alphamannosidase II (Lu et al, 2014). We found that exposing animals to swainsonine resulted in PVD defects that were indistinguishable from the effects of a null mutation in aman-2, either in combination with a partial loss of function allele of lect-2, or in wild type animals (Fig. 2E-G). In other words, the pharmacological inhibition of AMAN-2/Golgi alpha-mannosidase II activity resulted in the same phenotypic consequences as genetically inactivating or removing the enzyme. Collectively, these findings lead us to conclude that the catalytic activity of AMAN-2/Golgi alpha-mannosidase II is essential to support dendrite patterning in PVD. This further implies that $N$-glycosylation of a molecule expressed in PVD is crucial for normal dendrite arborization.

\footnotetext{
The presence of abnormal N-glycans in aman-2/Golgi alpha-mannosidase II mutants results in defective PVD arborization.
} 
In eukaryotes, $N$-glycosylation is initiated in the Endoplasmic Reticulum (ER) with the synthesis of a 14-saccharide glycan on the phosphorylated polyisoprenol lipid dolichol-PP (Stanley et al., 2015). Subsequently, the saccharide is transferred by a multiprotein complex termed oligosaccharyltransferase (OST) from dolichol-P-P to the aspartate within a NXS/T motif in nascent proteins as they are translocated into the ER (Stanley et al., 2015). As $N$-glycosylated proteins transit the Golgi, the glycans undergo a series of enzymatic modifications that add and remove specific sugar residues to lead to a wide array of possible $\mathrm{N}$-glycan structures (Fig.3A) (Stanley et al., 2015). For example, in one of the earlier steps, the enzyme MGAT1 adds a $\mathrm{N}$-acetylglucosamine residue to Man5Gn2 to form GnMan5Gn2 (Fig.3A). Genetically removing MGAT1 in mice results in complete loss of complex and hybrid $\mathrm{N}$-glycans and early embryonic death, demonstrating that these $N$-glycans are essential for mammalian development (loffe \& Stanley, 1994; Metzler et al, 1994). GnMan5Gn2 is the substrate for AMAN-2/MAN2A, which sequentially removes two mannose residues to form GnMan3Gn2 (Fig.3A) (Stanley et al., 2015). These reactions are followed by either removal or addition of additional sugars, or modification by a host of other conserved enzymes that lead to either complex or paucimannose $N$-glycans (Fig.3A). To determine which specific $N$ glycans are missing in aman-2 mutants, and are therefore required for branching of PVD dendrites, we systematically tested whether mutations in any of the genes downstream of aman-2 (including hex-2/hexosaminidase, hex-3/hexosaminidase, fut-8/FUT8 Fucosyltransferase, and gly-20/MGAT II) would also enhance the partial lect-2 loss of function allele. We found that removing the genes encoding these enzymes alone, or in combination, did not enhance the partial lect-2 loss of function allele (Fig.EV3A). Mutating MGAT1/N-acetylglucosaminyltransferase-I (in worms encoded by three paralogous genes gly-12, gly-13, gly-14) (Chen et al, 1999; Chen et al, 2003), which acts immediately before AMAN-2/Golgi alpha-mannosidase II, also showed no effects 
(Fig.EV3B). Collectively, these findings suggest that no lack of specific $N$-glycans downstream of MGAT1, or of AMAN-2, alone are responsible for the observed defects in PVD dendrites.

Previous structural studies of $\mathrm{N}$-glycans in aman-2(tm1078) null mutant animals (Paschinger et al, 2006) established that loss of aman-2/Golgi alpha-mannosidase II in C. elegans caused (1) a loss of the normal products of AMAN-2, including complex Nglycans (Fig.3A, shaded in green) and (2) a buildup of GnMan5Gn2, the substrate of AMAN-2 (Fig.3A)(Paschinger et al., 2006). This GnMan5Gn2 intermediate was found to serve as substrate for enzymes further downstream (including FUT-8/Fut8 Fucosyltransferase and PCT/Phosphorylcholine-transferase) leading to the appearance of abnormal $\mathrm{N}$-glycans, not normally present in wildtype animals (Fig.3a, shaded in red) (Paschinger et al., 2006). To determine whether the defects in PVD branching were caused by the absence of wild type $N$-glycans, or the presence of abnormal GnMan5Gn2 N-glycans, we mutated both MGAT1 and AMAN-2 in the partial loss of function backgrounds of lect-2 and $m n r-1$. The prediction was that, if the enhancement of the partial loss of function alleles lect-2 or mnr-1 by loss of aman-2 is caused by abnormal $N$-glycans, then removal of MGAT1, the preceding enzyme would suppress that enhancement. Indeed, loss of MGAT1 did suppress the enhanced phenotypes in lect-2; aman-2 and mnr-1; aman-2 double mutants (Fig.3B-D). These data indicate that one or more structurally abnormal $N$-glycans with a terminal $N$-acetylglucosamine are responsible for the observed defects in PVD patterning.

\section{DMA-1/LRR-TM N-glycosylation is changed in aman-2/Golgi alpha-} mannosidase II mutants.

Since we demonstrated that (1) aman-2/Golgi alpha-mannosidase /l genetically interacts with the Menorin pathway, and (2) AMAN-2/Golgi alpha-mannosidase II activity 
is required cell-autonomously in PVD to regulate branching, we hypothesized that AMAN-2/Golgi alpha-mannosidase II directly regulates $\mathrm{N}$-glycans on at least one component of the Menorin complex in PVD. Treatment of whole worm lysates with the bacterial PNGase F glycosidase, which cleaves all $N$-glycans from Asn, resulted in distinct downward shifts in molecular weight of both DMA-1 and KPC-1, indicating that $N$-glycans were present on both proteins in vivo and had been removed (Fig.3E,EV4C). Thus, both PVD-expressed proteins, DMA/LRR-TM and KPC-1/Furin, are $N$ glycosylated, consistent with a previous report for DMA-1/LRR-TM (Feng et al, 2020). Another cell-autonomous factor and possible candidate, HPO-30/Claudin (Smith et al, 2013), contains no predicted $N$-glycan consensus motifs.

We next determined whether loss of AMAN-2 resulted in altered N-glycosylation. Interestingly, the absence of aman-2/Golgi alpha-mannosidase /I resulted in a clear increase in DMA/LRR-TM molecular weight, whereas the size of KPC-1/Furin remained unaffected (Fig.3F,EV4C). The upward shift in DMA-1 size following the loss of aman-2 is consistent with our genetic data establishing that the presence of larger, abnormal GnMan5Gn2 N-glycans gives rise to the PVD mutant phenotype. To determine what types of $N$-glycans are attached to DMA-1 in wild type and aman-2 mutant backgrounds, we treated lysates with additional endoglycosidases: Endo $\mathrm{H}$, which cleaves hybrid/highmannose $\mathrm{N}$-glycans, and Endo $\mathrm{D}$, which cleaves only paucimannose $\mathrm{N}$-glycans. Based on the size of the shifts observed, we conclude that in wildtype animals, DMA-1 possesses primarily, but not exclusively, hybrid/high-mannose $N$-glycans with a smaller amount of paucimannose $\mathrm{N}$-glycans. In contrast, in the absence of AMAN-2, all $\mathrm{N}$ glycans on DMA-1/LRR-TM were converted to hybrid/high-mannose type (likely GnMan5Gn2-derived N-glycans) with no or little detectable paucimannose $N$-glycans (Fig.3G,EV4A,B). Additionally, proteomic studies identified C. elegans SAX-7/L1CAM and LECT-2/Chondromodulin II as glycoproteins (Kaji et al, 2007), which we confirmed 
by a shift in molecular weight upon digestion of all $N$-glycans by PNGase $F$ (Fig.EV4D,E). However, in the absence of aman-2/Golgi alpha-mannosidase II, neither SAX-7/L1CAM and LECT-2/Chondromodulin II displayed obvious changes in molecular weight, suggesting that they did not carry abnormal $N$-glycans in an aman-2 mutant background. Collectively, our data show that among the $N$-glycosylated proteins of the Menorin complex, only DMA-1/LRR-TM was significantly affected by the loss of aman2/Golgi alpha-mannosidase II and carried altered $N$-glycans in aman-2 null animals.

\section{AMAN-2/Golgi alpha-mannosidase II modulates N-glycans on DMA-1/LRR-TM}

\section{to regulate PVD morphogenesis.}

The DMA-1/LRR-TM receptor contains four predicted $N$-glycosylation motifs, all of which reside in leucine rich repeats (Fig.4A). To establish whether the $N$-glycosylation of DMA-1/LRR-TM is essential for its role in PVD dendrite branching, we mutated all four sites, alone and in combinations. Using CRISPR/Cas9-based genome editing, we converted the asparagine residues of the four predicted $\mathrm{N}$-glycan attachment sites to glutamine to maintain chemical similarity but eliminate the possibility of $N$-glycosylation. We found that only when abolishing predicted $\mathrm{N}$-glycan attachment site 4 (N386), alone or in combination with other sites, was PVD quaternary branching compromised (Fig.4B). These results reveal that $N$-glycosylation of DMA-1/LRR-TM is required for its role in PVD patterning of quaternary branches and highlight the importance of N386 within a membrane proximal LRR repeat. We then assessed whether abolishing $\mathrm{N}$ glycan attachment sites in an aman-2/Golgi alpha-mannosidase /I loss of function background had any effects on dendrite patterning. Analysis of different site-specific mutations revealed that some $N$-glycosylation sites on DMA-1/LLR-TM enhance the severity of PVD dendrite branching defects in an aman-2 mutant background (Fig.4C-D). The results in an aman-2 mutant background suggest that having some type of $N$-glycan 
on site 4 of DMA-1/LRR-TM, even if abnormal, is better than having no $\mathrm{N}$-glycan at all (cf. S3 and S123); second having such abnormal N-glycans on sites 1-3 further compromises DMA-1 function during PVD development (cf. S4 in control vs aman-2 mutant background, Fig.4B,C). Lastly, the mutant phenotype resulting from a presumptive loss of all N-glycans on DMA-1 (S1234) is enhanced in an aman-2 mutant background, suggesting that $N$-glycosylated proteins other than DMA-1 may serve additional functions during PVD morphogenesis or that abnormal $\mathrm{N}$-glycans on cryptic $\mathrm{N}$ glycosylation sites further compromise function (Fig.4C).

\section{DISCUSSION}

While prior studies established the importance of $\mathrm{N}$-glycosylation during neuronal development, our studies establish an important role for specific classes of $\mathrm{N}$-glycans in mediating neuronal development, and specifically dendrite patterning. They suggest that the DMA-1/LRR-TM receptor in PVD must be decorated with specific hybrid/highmannose or paucimannose $N$-glycans as a result of AMAN-2 activity and that these specific $N$-glycans are important for functioning of the Menorin complex in PVD dendrite morphogenesis. A possible explanation is that the $N$-glycans on specific $N$-glycosylation sites in DMA-1/LRR-TM function permissively to maintain high affinity binding of DMA1/LRR-TM to other members of the Menorin complex through specific $N$-glycans (Fig.4E). This interaction could be compromised by the formation of abnormal glycans in the absence of AMAN-2 leading to destabilization of the complex. Therefore, our genetic and biochemical data, together with analytical data of N-glycans in aman-2/Golgi alphamannosidase /l mutants (Paschinger et al., 2006), underscore the importance of AMAN2/Golgi alpha-mannosidase II as a linchpin for the creation of complex and paucimannose $\mathrm{N}$-glycans, and avoidance of larger, abnormal hybrid and high-mannosetype $N$-glycans. Since metabolite availability can influence $N$-glycan synthesis and flux 
(reviewed in (Dennis et al, 2009)), these findings also raise the possibility that environmental factors can intersect with intrinsic genetic programs to regulate extracellular adhesion complexes during neural development by modulating $N$ glycosylation.

Previous studies demonstrated that $N$-glycosylation is important for folding and surface localization of cell adhesion molecules and axon guidance factors, such as L1CAMs and ephrins, respectively (Sekine et al., 2013; Medina-Cano et al., 2018; Mire et al., 2018). On the other hand, in vitro experiments suggested that $N$-glycans can regulate protein-protein interactions of cell adhesion molecules (Fogel et al, 2010; Labasque et al, 2014). Our findings demonstrate in vivo, that not only $N$-glycans per se, but that specific classes of $\mathrm{N}$-glycan structures are important to modulate cell-cell signaling, and possibly, receptor-ligand binding and complex formation. This is reminiscent of the role of $O$-fucose glycans on the Notch receptor extracellular domain, which affect its signaling and ligand interactions (Moloney et al, 2000). Given that over $70 \%$ of proteins transiting the secretory pathway are $N$-glycosylated (Apweiler et al., 1999), these findings raise the possibility that specific $N$-glycan structures are important determinants to regulate the interactions of extracellular complexes during nervous system development more broadly and could contribute to the specificity that is required in the nervous system. In this context it is interesting to note that over 70 congenital disorders of glycosylation have been described that affect genes in the $N$-glycosylation pathway (Freeze, 2006; Ng \& Freeze, 2018), of which many are associated with intellectual disability or other neurological symptoms (Jaeken \& Peanne, 2017; Chang et al., 2018). While no mutations in Golgi alpha-mannosidase II in humans have been described to date, it is conceivable that such mutations exist, and may result in neurological phenotypes. Regardless, our studies provide the conceptual framework for 
studies into developmental defects of the nervous system in mutants of genes involved in $N$-glycosylation and this growing class of congenital disorders.

\section{ACKNOWLEDGEMENTS}

We thank Yehuda Salzberg, Pamela Stanley, Robert Townley, Peri Kurshan and members of the Bülow laboratory for comments on the manuscript and helpful discussions during the course of this work. We thank Kang Shen, lain Wilson, Shohei Mitani for reagents, and Yuji Kohara for the $y k 11 g 705$ cDNA clone. We are grateful to Meera Trivedi for sharing the $d z I s 117$ strain prior to publication. Some strains were provided by the Caenorhabditis Genome Center (funded by the NIH Office of Research Infrastructure Programs P40 OD010440). This work was supported by grants from the National Institute of Health (NIH): R01NS096672 and R21NS111145 to HEB; F31NS100370 to MR; T32GM007288 and F31HD066967 to CADB; P30HD071593 to Albert Einstein College of Medicine. NJRS was the recipient of a Colciencias-Fulbright Fellowship and HEB of an Irma T. Hirschl/Monique Weill-Caulier research fellowship.

\section{AUTHOR CONTRIBUTIONS}

Conceptualization Ideas: MR, HEB; Validation: MR; Formal Analysis: MR, HEB; Investigation: MR; Resources: NJRS, CADB; Writing - Original Draft: MR; Writing Review \& Editing: MR, NJRS, CADB, HEB; Visualization Preparation: MR; Project Administration: HEB; Funding Acquisition: MR, NJRS, CADB, HEB.

\section{DECLARATION OF INTERESTS}

The authors declare no competing interests. 
bioRxiv preprint doi: https://doi.org/10.1101/2021.10.11.464022; this version posted October 13, 2021. The copyright holder for this preprint (which was not certified by peer review) is the author/funder. All rights reserved. No reuse allowed without permission.

\section{FIGURES}
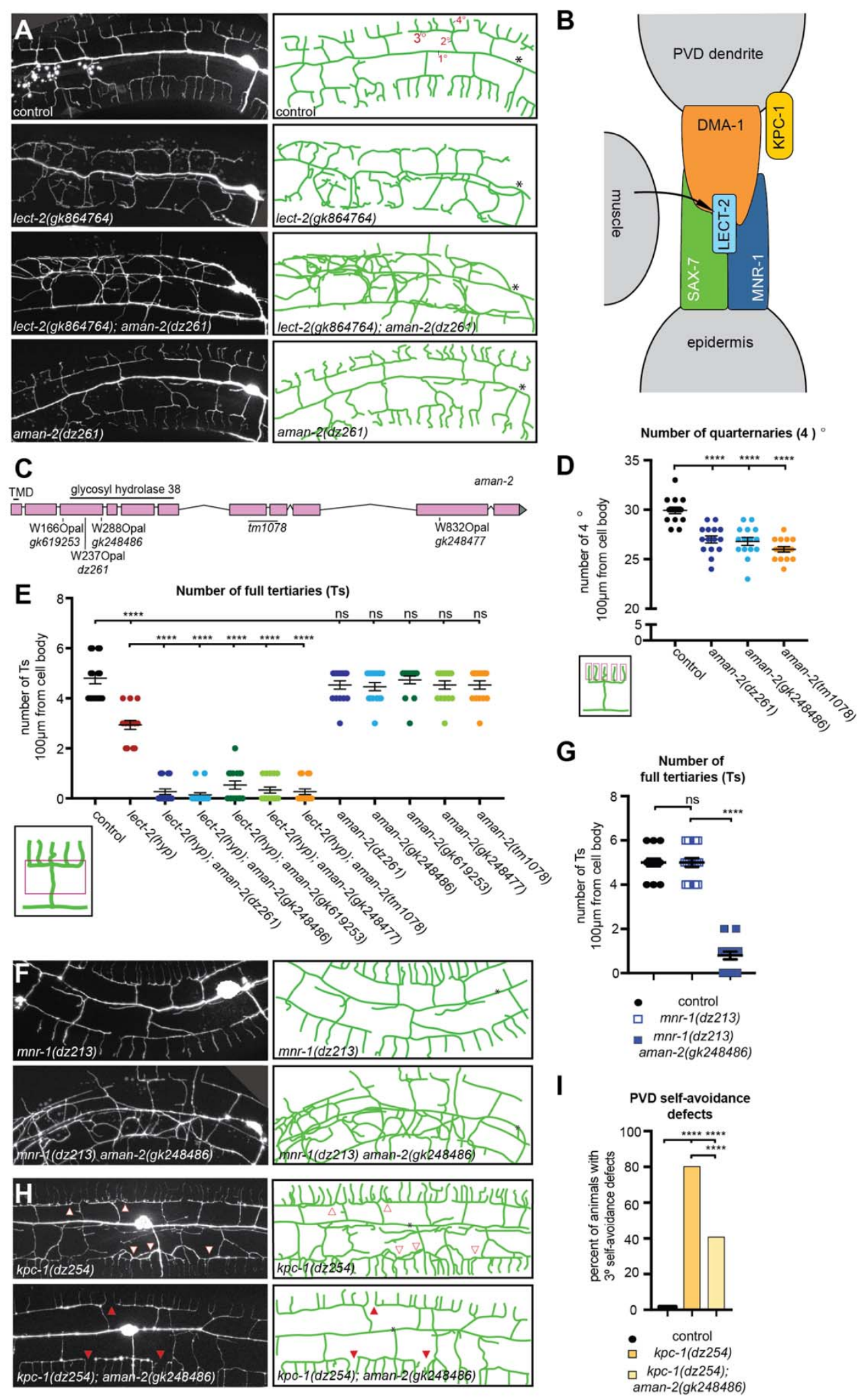

Figure 1 
Figure 1 AMAN-2/Golgi alpha-mannosidase II is required for PVD dendrite patterning.

(A) Fluorescent images (left panels) and tracings (right panels) of PVD of the indicated genotypes. PVD is visualized by the wdls52 transgene. Primary $\left(1^{\circ}\right)$, secondary $\left(2^{\circ}\right)$, tertiary $\left(3^{\circ}\right)$, and quaternary $\left(4^{\circ}\right)$ dendrites are indicated, and the cell body is marked with an asterisk. Anterior is to the left and dorsal is up in all panels.

(B) Schematic of the Menorin complex, including DMA-1/LRR-TM, SAX-7/L1CAM, MNR$1 /$ Menorin, and LECT-2/Chondromodulin II as well as the negative regulator KPC1/Furin.

(C) Genomic environs of aman-2. An N-terminal transmembrane domain (TMD) is indicated as it encodes a type II transmembrane protein. All alpha-mannosidase II proteins contain a glycosyl hydrolase 38 domain. Four nonsense alleles, and one deletion allele (tm1078) of aman-2 are denoted.

(D) Quantification of the number of quaternary branches (indicated in schematic) in different aman-2 alleles and in wild type control animals. All loss of function alleles of aman-2 show a significant decrease in quaternary branch number. Data are represented as mean \pm SEM. Statistical significance was calculated using the Kruskal-Wallis test and is indicated $\left({ }^{* * * *} p \leq 0.0001\right) . n=15$ for all genotypes.

(E) Quantification of the number of "Ts" (formed by secondary and tertiary branches as shown in schematic) in the genotypes indicated. Data are represented as mean \pm SEM. Statistical significance was calculated using the Kruskal-Wallis test and is indicated $\left({ }^{* * *} p \leq 0.0001\right.$; ns $=$ not significant $) . n=15$ for all genotypes.

(F) Fluorescent images and tracings of PVD in $m n r-1(d z 213)$ hypomorphic animals alone and in combination with an aman-2(null) mutant. The $d z 213$ introduces a L135F missense mutation in the DUF2181 domain of MNR-1/Menorin. PVD is visualized by the $d z I s 53$ transgene. The cell body is marked with an asterisk.

(G) Quantification of the number of "Ts" in genotypes indicated and traced in (F). The loss of aman-2 severely enhances the mnr-1(dz213) phenotype. Data are represented as mean \pm SEM. Statistical significance was calculated using the MannWhitney test and is indicated ${ }^{* * * *} p \leq 0.0001$; ns $=$ not significant). $n>23$ for all genotypes.

(H) Fluorescent images and tracings of PVD in $k p c-1(d z 254)$ hypomorph animals alone and in combination with an aman-2(null) mutant. PVD is visualized by the dzls53 transgene. White arrows indicate self-avoidance defects in tertiary branches. Red arrows show gaps between tertiary branches (no self-avoidance defects). The cell body is marked with an asterisk.

(I) Quantification of the percent of self-avoidance defects in genotypes indicated and traced in (G). The loss of aman-2 suppresses defects in the kpc-1(dz254) phenotype. Data are represented as mean. Statistical significance was calculated using the Ztest and is indicated $\left({ }^{* * *} p \leq 0.0001\right) . n>15$ for all genotypes. 
A

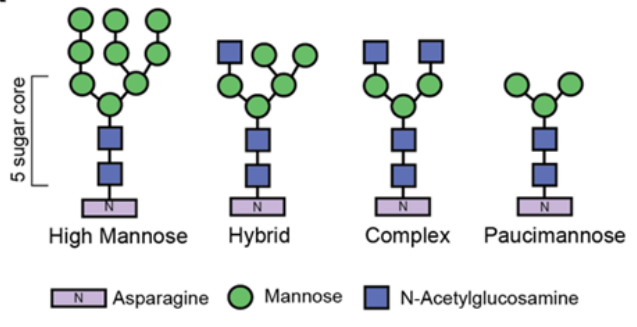

C

\begin{tabular}{|c|c|c|}
\hline \multicolumn{3}{|c|}{$\begin{array}{l}\text { Cell specific rescue of PVD defects in } \\
\text { lect-2(hyp); aman-2(null) \& } \\
\text { mnr-1(hyp); aman-2(null) mutants }\end{array}$} \\
\hline promoter & & rescued lines \\
\hline PVD & AMAN-2 CDNA & $4 / 43 / 3$ \\
\hline muscle & AMAN-2 CDNA & $0 / 30 / 3$ \\
\hline epidermis & AMAN-2 CDNA & $0 / 30 / 3$ \\
\hline PVD & $\begin{array}{l}\mathrm{AMAN}-2 \triangle \mathrm{C} \text { cDNA } \\
\end{array}$ & $0 / 30 / 3$ \\
\hline
\end{tabular}

B

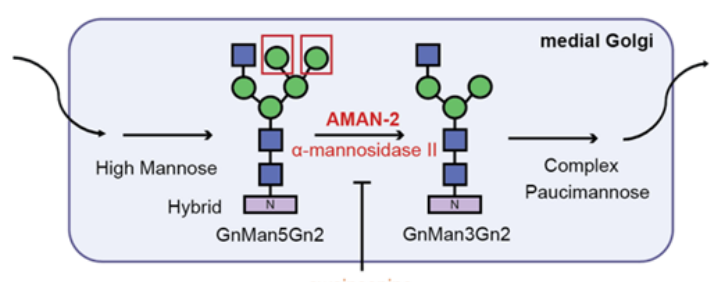

D Ce AMAN-2

$\begin{array}{ll}\text { Ce } & \text { AMAN-2 } \\ \text { Hs } & \text { MAN2A1 }\end{array}$ Mm MAN2A1 Dr Man2a1 Dm Alpha-Man-lla 285 KVGWSIDPFGHGSIVPYLLSGANFEGTIQRIHY

Ce AMAN-2 HS MAN2A1 $\mathrm{Mm}$ MAN2A1
$\mathrm{Dr}$ Man2a1 360 DLRSHIMPFYSY DIPHTCGPEPS VCCQFDFRRMP
343 D ILCHMMPF Y Y I PHTCGPD I I CCQF DFKRLP 343 D I LCHMMPF Y S D I PHTCGPDPKICCQF DFKRLP 342 D I LCHMMPF Y SY DIPH TCGPDPK I CCQFDFKRLP 341 ILCHMMF Dm Alpha-Man-lla 345 DLLTHNMPFDIYSIKGSCGPHPFICLNFDFRKIP

Ce AMAN-2 Hs MAN2A1 Mm MAN2A1 Dr Man2a1 Dm Alpha-Man-lla

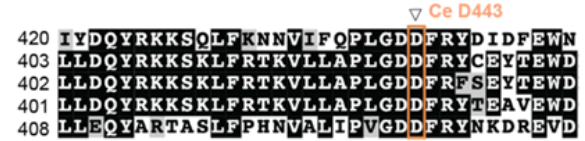

$\mathbf{F}$

E
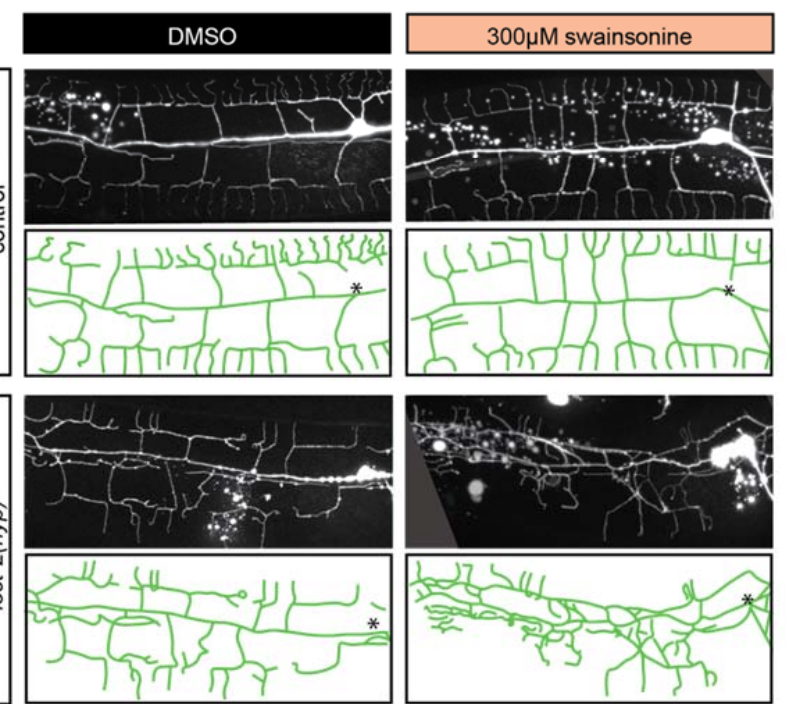

F Number of full tertiaries (Ts)

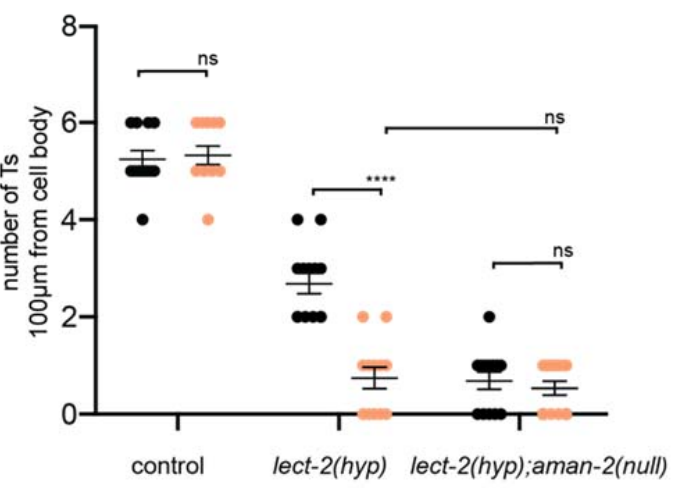

- DMSO $300 \mu \mathrm{M}$ swainsonine

G Number of quarterneries $\left(4^{\circ}\right)$

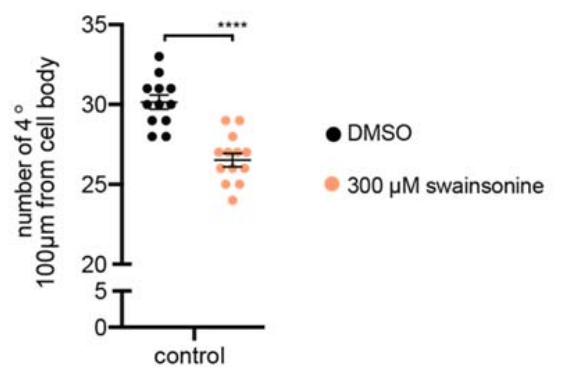

Figure 2

Figure 2 AMAN-2/Golgi alpha-mannosidase II requires enzymatic activity in PVD to form higher order branches

(A) Types of $N$-linked glycans. The shared penta-saccharide core consists of two $N$ acetylglucosamines (blue squares) and 3 mannoses (green circles) attached onto an 
Asparagine residue with an N-X-S/T consensus site. Glycan types vary by identity of additional sugars onto the pentasaccharide core.

(B) Drawing showing the enzymatic activity of AMAN-2 in the medial Golgi. AMAN-2 cleaves two specific $\alpha 1,3$ and $\alpha 1,6$ mannose linked residues boxed in red, allowing for the formation of complex and paucimannose type $N$-glycans. Arrows denote other enzymes. Swainsonine specifically inhibits enzymatic activity of alpha-mannosidase II. (Man= mannose, $\mathrm{Gn}=\mathrm{N}$-acetylglucosamine).

(C) Table showing cell-specific rescue experiments of PVD defects. AMAN-2 cDNA is expressed under the control of PVD, muscle, and epidermal specific promoters in the indicated double mutant backgrounds. Rescue is defined by restoration of the enhanced PVD phenotype back to that of the single hypomorphic mutants alone. 25 transgenic animals and their non-transgenic siblings were scored for each line.

(D) Multiple sequence alignment of human MAN2A1 (Hs; acc\# NP_002363.2), mouse MAN2A1 (Mm; acc\# NP_032575.2), zebrafish Man2a1 (Dr; acc\# NP_001103497.2), fruit fly Alpha-Man-Ila (Dm; acc\# NP_650494.2) and C. elegans AMĀN-2 (Ce; acc\# NP_505995.2) created by COBALT (constrained based multiple sequence alignment tool). Conserved catalytic sites D306 (black arrow) and D443 (white arrow) are boxed in orange.

(E) Fluorescent images and tracings of wild type control (top) and lect-2(gk846764) hypomorphic animals (bottom) fed on plates with $300 \mu \mathrm{m}$ swainsonine vs a DMSO control. PVD is visualized by the wyls581 transgene. The cell body is denoted with an asterisk. Anterior is to the left and dorsal is up in all panels.

(F) Quantification of the number of "Ts" in denoted genetic backgrounds (aman-2 null is gk248486). Black data points indicate DMSO and orange data points show swainsonine treated animals. Data are represented as mean \pm SEM. Statistical significance was calculated using the Mann-Whitney test and is indicated $\left({ }^{* * * *} p \leq\right.$ 0.0001 ; ns= not significant). $\mathrm{n}=12$ for all genotypes.

(G) Quantification of the number of quaternary dendrites in wild type control animals fed on plates with and without $300 \mu \mathrm{m}$ swainsonine. Animals treated with swainsonine show a significant decrease in quaternary branch number, akin to the data in Figure 1C. Data are represented as mean \pm SEM. Statistical significance was calculated using the Mann-Whitney test and is indicated $\left({ }^{* * *} p \leq 0.0001\right)$. $n=12$ for each experiment. 

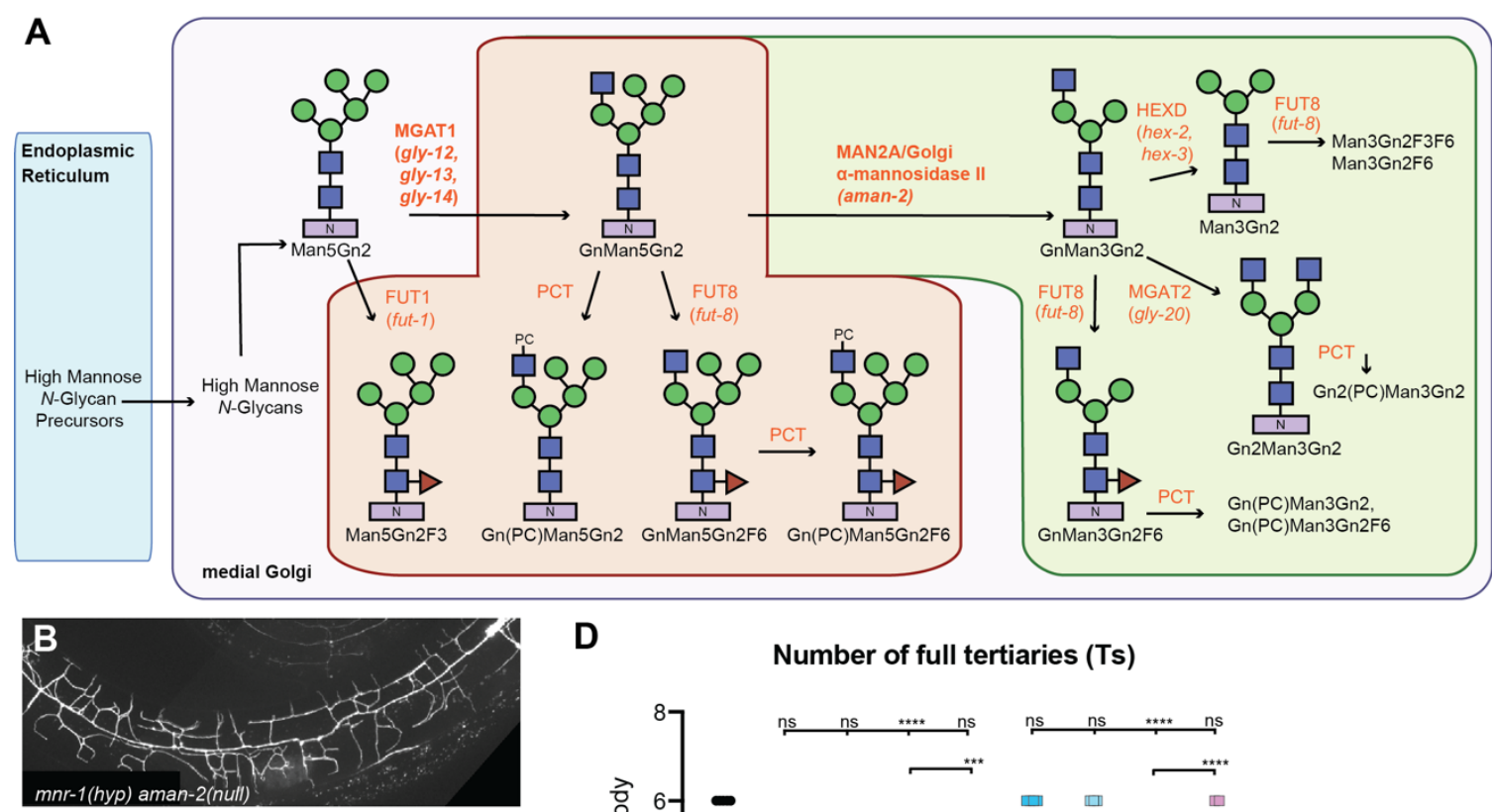

D Number of full tertiaries (Ts)
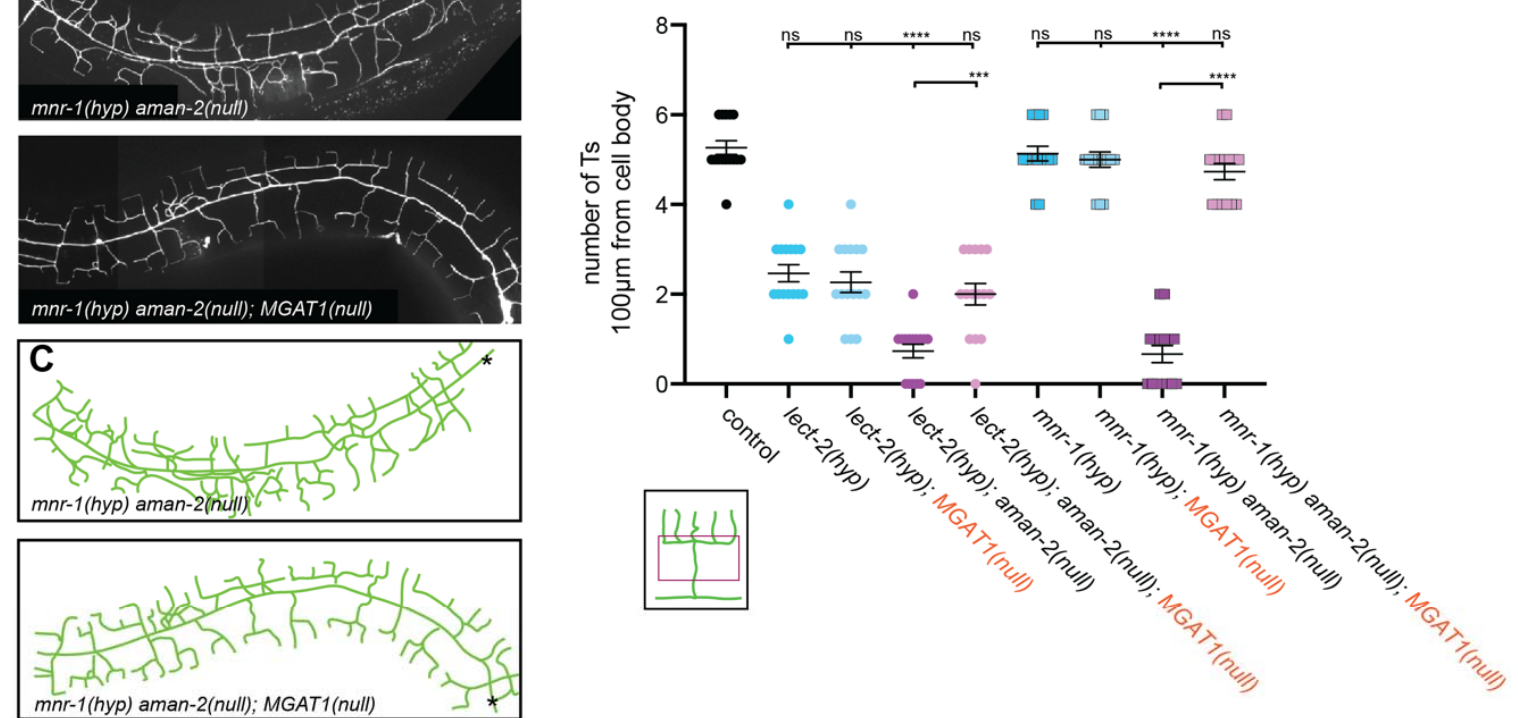

E
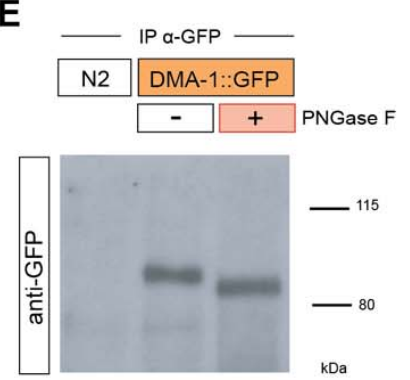

F

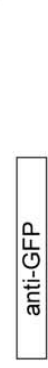

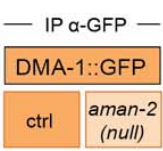

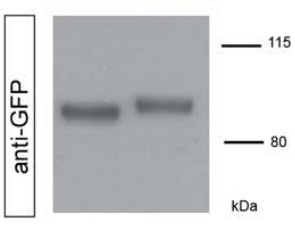

G

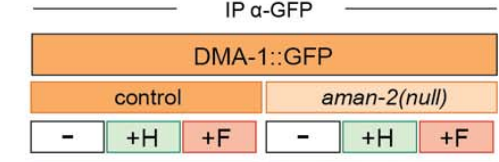

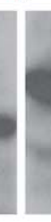

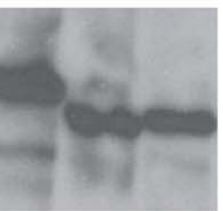

$-115$

$-80$

$\mathrm{kDa}$

Figure 3

Figure 3 The presence of abnormal $N$-glycans in mutants of AMAN-2/Golgi alphamannosidase II results in defects in PVD arborization.

(A) Schematic of the conserved $N$-glycosylation pathway in C. elegans. The blue box represents the Endoplasmic Reticulum, while the purple box represents the medial Golgi. Glycan residues are consistent with Figure 2A, with the addition of red triangles denoting fucose residues. Arrows and orange text represent enzymes. The green area marks wild type $N$-glycan chains whereas the red area represents 
abnormal $\mathrm{N}$-glycan chains that arise in the absence of AMAN-2. The glycans in the green area are not formed in the absence of AMAN-2. (Man= mannose, $\mathrm{Gn}=\mathrm{N}-$ acetylglucosamine, $\quad \mathrm{F}=$ fucose, $\quad \mathrm{PC}=$ phosphorylcholine, $\quad$ MGAT1=Nacetylglucosaminyltransferase I, FUT=fucosyltransferase, HEXD=hexosaminidase).

(B-C) Fluorescent images (top) and tracings (bottom) of $m n r-1$ (dz213) in an aman2(gk248486) and an aman-2(gk248486); MGAT-1(null) background. An MGAT null mutant lacks the three $C$. elegans paralogs: gly-12, gly-13, and gly-14. PVD is visualized by the wyls581 transgene. The cell body is denoted with an asterisk. Anterior is to the left and dorsal is up in all panels.

(D) Quantification of "Ts" of denoted genotypes. Data are represented as mean \pm SEM. Statistical comparisons were performed using the Kruskal-Wallis test. Statistical significance is indicated $\left({ }^{* * *} \mathrm{p} \leq 0.001,{ }^{* * * *} \mathrm{p} \leq 0.0001\right.$, ns=not significant). $\mathrm{n}=15$.

(E) Western blot against GFP in C. elegans lysate expressing no transgenes (N2) and expressing DMA-1::GFP (qyls369), after precipitating with anti-GFP antibody. The red boxed plus sign indicates that the lysate is treated with the PNGase $F$ glycosidase. The downwards size shift reveals that $N$-glycan structures are present on DMA-1. Ladder is marked in kilodaltons $(\mathrm{kDa})$. The GFP tag contains no $\mathrm{N}$ glycosylation sites.

(F) Western blot against GFP in C. elegans lysate DMA-1::GFP (qyls369), after precipitating with anti-GFP antibody. Control indicates an otherwise wild type background as opposed to an aman-2(gk248486) null background. The downward size shift in the mutant reveals that loss of aman-2 alters the identity of $N$-glycan structures on DMA-1.

(G) Western blot against GFP in C. elegans lysate DMA-1::GFP (qyls369), after precipitating with anti-GFP antibody. Control indicates an otherwise wild type background as opposed to an aman-2(gk248486) null background. The red boxed $+F$ indicates that the lysate is treated with the PNGase $F$ glycosidase, while the green boxed $+\mathrm{H}$ corresponds to the Endo $\mathrm{H}$ glycosidase, which cleaves highmannose and hybrid type $N$-glycans. For complementary experiments using the Endo D glycosidase, which cleaves paucimannose type $N$-glycans, see Fig.EV4B. Size shifts indicate that some hybrid/high-mannose structures are present on DMA-1 (left), and that the aman-2 mutant results in only hybrid/high-mannose structures on DMA-1 (right). 
A

DMA-1/LRR-TM

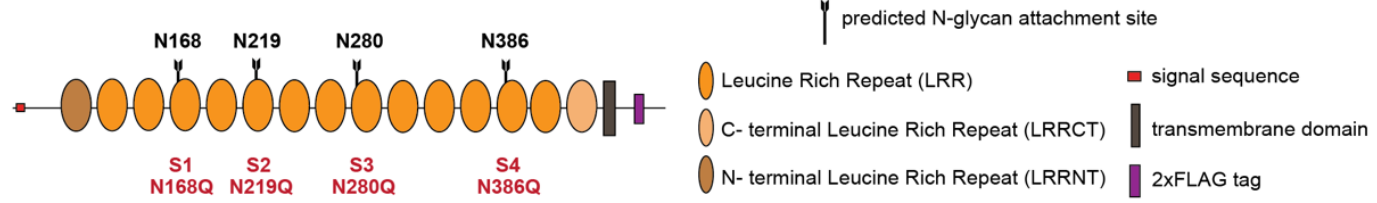

B N to Q site mutations of DMA-1::2xFLAG

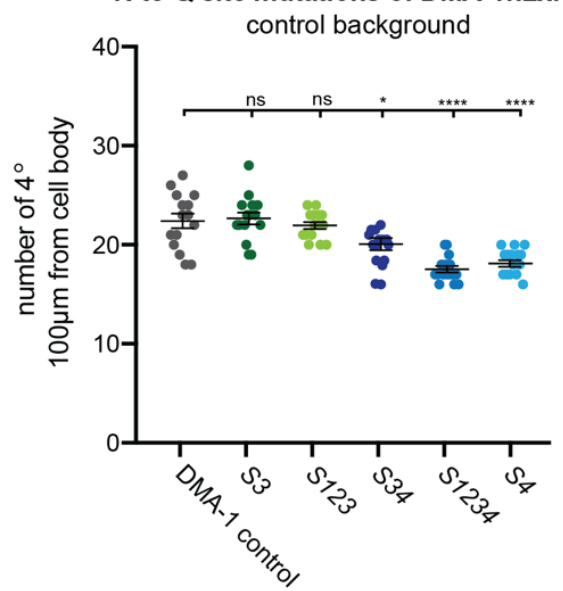

C

N to $Q$ site mutations of DMA-1::2xFLAG
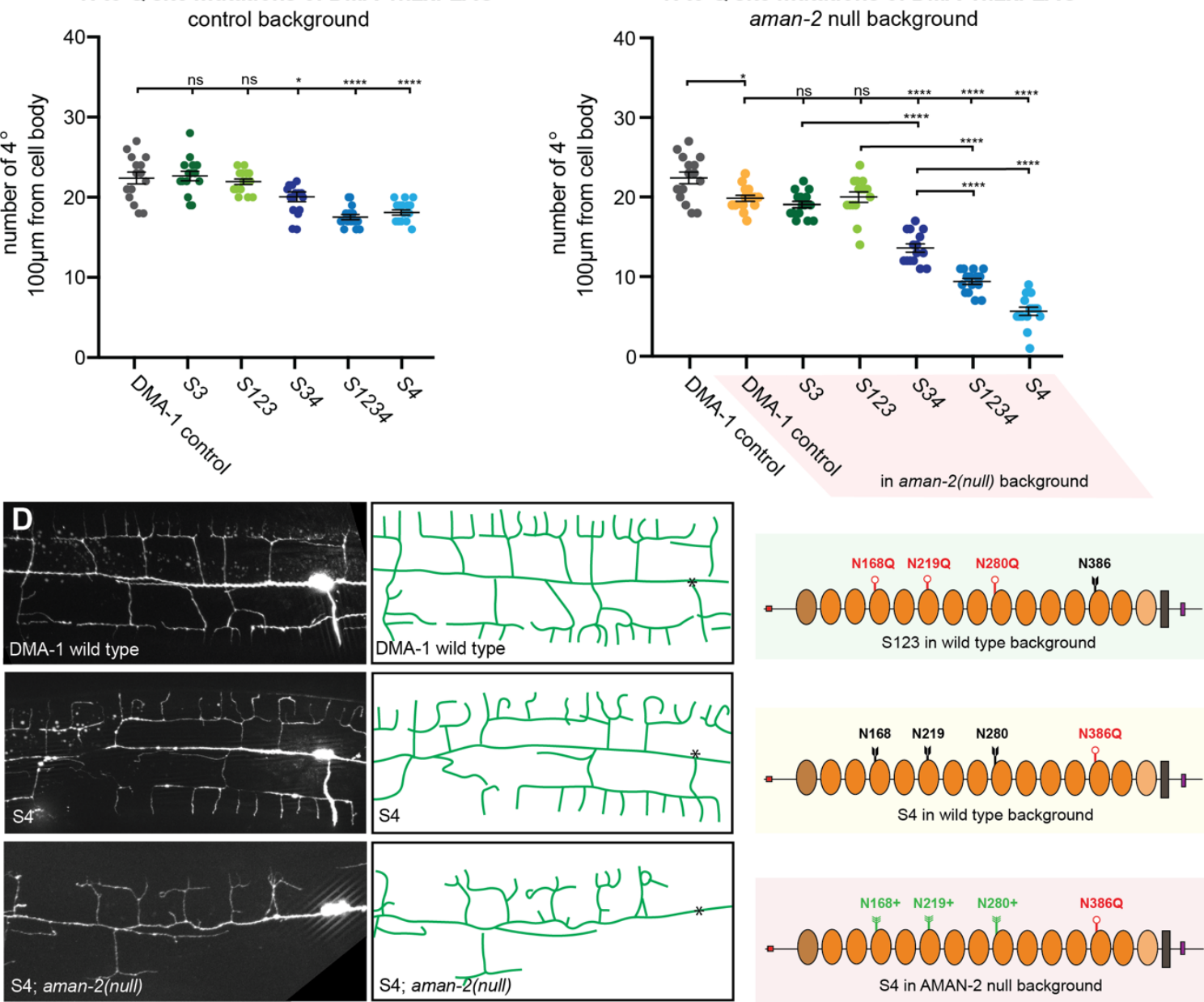

S4 in wild type background

E
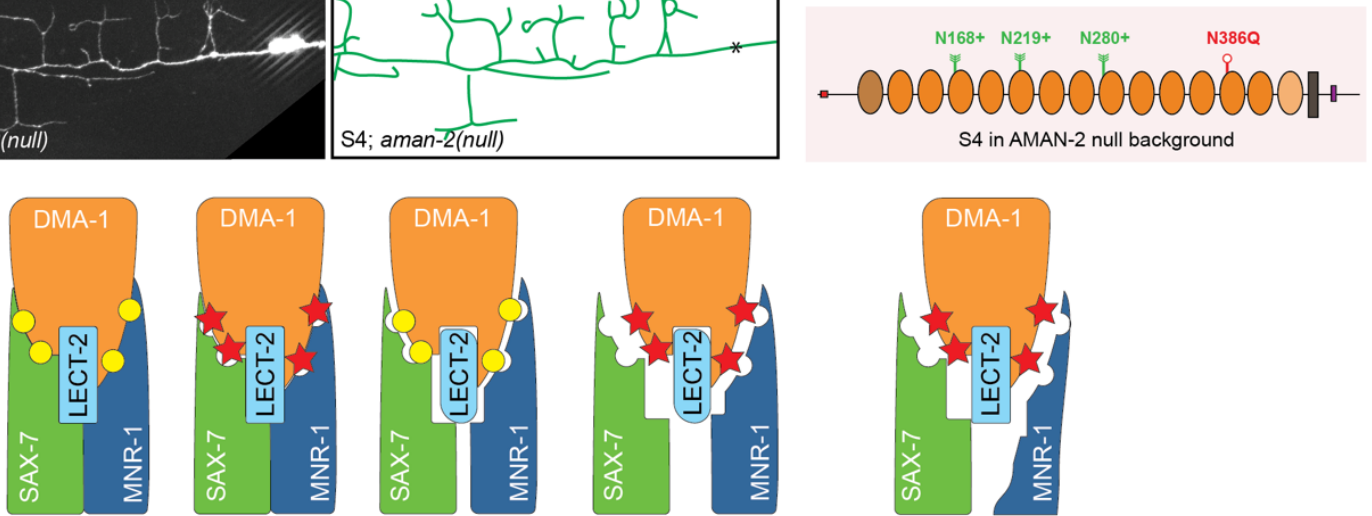

wild type

aman-2(null)

lect-2(hyp)

lect-2(hyp);aman-2(null)

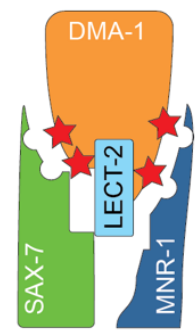

complex stability

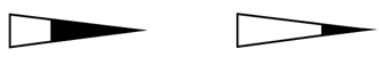

Figure 4 
Figure 4 AMAN-2/Golgi alpha-mannosidase II modulates $N$-glycans on DMA1/LRR-TM to regulate PVD morphogenesis

(A) Schematic of DMA-1/LRR-TM with mutated N-glycan attachment sites S1-S4 indicated.

(B) Quantification of the number of quaternary branches in DMA-1::2xFLAG control animals and animals with combinations of DMA-1::2xFLAG $N$-glycan attachment sites mutated. Note that DMA-1::2xFLAG control animals display a slightly reduced number of quaternary dendrites compared to wild type animals (Fig.EV3C). Data are represented as mean \pm SEM. Statistical significance was calculated using the Kruskal-Wallis test and is indicated $\left({ }^{* * *} p \leq 0.0001\right.$, ns=not significant). $n=15$ for all genotypes.

(C) Quantification of the number of quaternary branches in DMA-1::2xFLAG control animals alone and in combination with an aman-2(gk248486) null mutant (shaded in red). Control data is identical as in (B) and shown for comparison only. Data are represented as mean \pm SEM. Statistical significance was calculated using the Kruskal-Wallis test and is indicated $\left({ }^{*} p \leq 0.05,{ }^{* * *} p \leq 0.0001\right.$, ns=not significant). $n=$ 15 for all genotypes.

(D) Fluorescent images (left) and tracings (center) of PVD in animals of denoted backgrounds (aman-2(null) is gk248486). S4 corresponds to the endogenous alteration of $N$-glycan attachment site N386 of DMA-1. PVD is visualized by the $d z I s 117$ transgene. The cell body is marked with an asterisk. The schematics on the right detail the molecular context of the indicated backgrounds. Green indicates a relatively normal PVD structure, yellow a slightly compromised structure, and red a heavily defective arborization. Black attachments indicate wild type, red indicate blocked sites, and green indicates larger abnormal $N$-glycans chains.

(E) The proposed model of how the loss of aman-2 can modulate $N$-glycans on DMA-1, and potentially the binding of the Menorin complex as a whole. Yellow circles represent normal $\mathrm{N}$-glycan chains, while red stars represent abnormal $N$-glycans produced in an aman-2 mutant background. Putative complex stability is indicated below. 


\section{MATERIALS AND METHODS}

\begin{tabular}{|c|c|c|}
\hline REAGENT or RESOURCE & SOURCE & IDENTIFIER \\
\hline \multicolumn{3}{|l|}{ Bacterial and Virus strains } \\
\hline E. coli: OP50 & $\begin{array}{l}\text { Caenorhabditis Genetics } \\
\text { Center }\end{array}$ & OP50 \\
\hline \multicolumn{3}{|l|}{ Experimental Models: Organisms/Strains } \\
\hline C. elegans: wildtype isolate & $\begin{array}{l}\text { Caenorhabditis Genetics } \\
\text { Center }\end{array}$ & $\mathrm{N} 2$ \\
\hline C. elegans: wdls52 II & Kind gift of David Miller & NC1687 \\
\hline C. elegans: wyls378 X & Kind gift of Kang Shen & wyls378 \\
\hline C. elegans: wyls581 IV & Kind gift of Kang Shen & wyls581 \\
\hline C. elegans: $d z l s 117$ II & This paper & $d z I s 117$ \\
\hline $\begin{array}{l}\text { C. elegans: lect-2(dz249[lect- } \\
\text { 2::mNeonGreen::3XFLAG]) II }\end{array}$ & Diaz-Balzac et al, 2016 & EB2724 \\
\hline $\begin{array}{l}\text { C. elegans: lect-2(dz249[lect- } \\
\text { 2::mNeonGreen::3XFLAG]) II; him-5(ok1896) V }\end{array}$ & Diaz-Balzac et al, 2016 & EB3894 \\
\hline $\begin{array}{l}\text { C. elegans: dzls53 ddls290 (SAX-7::GFP::3XFLAG) } \\
\text { II; him-5(ok1896) V }\end{array}$ & Diaz-Balzac et al, 2016 & EB2808 \\
\hline C. elegans: qyls369 X & Kind gift of Kang Shen & qyls369 \\
\hline C. elegans: wyls581 IV; qyls369 X & This paper & EB3534 \\
\hline $\begin{array}{l}\text { C. elegans: wyls581 IV; qyls369 X; aman- } \\
\text { 2(gk248486) V }\end{array}$ & This paper & EB3634 \\
\hline C. elegans: dzIs53 II; him-5(ok1896) V & This paper & EB2824 \\
\hline C. elegans: lect-2(gk864764) II; wyls378 X & This paper & EB2795 \\
\hline C. elegans: wdls52 lect-2(gk864764) II & This paper & EB2805 \\
\hline $\begin{array}{l}\text { C. elegans: kpc-1(dz254) l; wdls52 lect-2(gk864764) } \\
\text { II }\end{array}$ & This paper & EB2908 \\
\hline $\begin{array}{l}\text { C. elegans: wdls52 lect-2(gk864764) II; mnr-1(dz252) } \\
V\end{array}$ & This paper & EB2906 \\
\hline $\begin{array}{l}\text { C. elegans: wdls52 lect-2(gk864764) II; sax-7(dz253) } \\
\text { IV }\end{array}$ & This paper & EB2907 \\
\hline $\begin{array}{l}\text { C. elegans: wdls52 lect-2(gk864764) II; aman- } \\
\text { 2(dz261) V }\end{array}$ & This paper & EB2915 \\
\hline C. elegans: wyls581 IV; him-5(ok1896) V & This paper & EB2926 \\
\hline C. elegans: kpc-1(dz254) I; dzls53 II & This paper & EB2983 \\
\hline $\begin{array}{l}\text { C. elegans: kpc-1(dz254) I; dzls53 II; him-5(ok1896) } \\
\text { V }\end{array}$ & This paper & EB3282 \\
\hline $\begin{array}{l}\text { C. elegans: kpc-1(dz254) I; dzls53 II; aman- } \\
\text { 2(gk248486) V }\end{array}$ & This paper & EB3299 \\
\hline $\begin{array}{l}\text { C. elegans: lect-2(gk864764) II; wyls581 IV; him- } \\
\text { 5(ok1896) V }\end{array}$ & This paper & EB3061 \\
\hline C. elegans: dzIs53 II; mnr-1(dz213) V & This paper & EB3281 \\
\hline $\begin{array}{l}\text { C. elegans: wyls581 IV; mnr-1(dz213) aman- } \\
\text { 2(gk248486) V }\end{array}$ & This paper & EB3403 \\
\hline C. elegans: aman-2(gk248486) V & $\begin{array}{l}\text { Caenorhabditis Genetics } \\
\text { Center }\end{array}$ & VC20294 \\
\hline C. elegans: aman-2(gk248477) V & $\begin{array}{l}\text { Caenorhabditis Genetics } \\
\text { Center }\end{array}$ & VC20422 \\
\hline C. elegans: aman-2(gk619253) V & $\begin{array}{l}\text { Caenorhabditis Genetics } \\
\text { Center }\end{array}$ & VC40398 \\
\hline
\end{tabular}




\begin{tabular}{|c|c|c|}
\hline C. elegans: aman-2(tm1078) V & $\begin{array}{l}\text { Kind gift of the Shohei } \\
\text { Mitani }\end{array}$ & $\operatorname{tm} 1078$ \\
\hline C. elegans: lect-2(gk864764) II; wyls581 IV & This paper & EB3228 \\
\hline $\begin{array}{l}\text { C. elegans: lect-2(gk864764) II; wyls581 IV; aman- } \\
\text { 2(gk248486) V }\end{array}$ & This paper & EB3260 \\
\hline C. elegans: wyls581 IV; aman-2(gk248486) V & This paper & EB3261 \\
\hline $\begin{array}{l}\text { C. elegans: lect-2(gk864764) II; wyls581 IV; aman- } \\
\text { 2(gk248477) V }\end{array}$ & This paper & EB3293 \\
\hline $\begin{array}{l}\text { C. elegans: lect-2(gk864764) II; wyls581 IV; aman- } \\
\text { 2(gk619253) V }\end{array}$ & This paper & EB3294 \\
\hline C. elegans: wyls581 IV; aman-2(gk248477) V & This paper & EB3405 \\
\hline C. elegans: wyls581 IV; aman-2(gk619253) V & This paper & EB3406 \\
\hline C. elegans: dzls117 II; him-5(ok1896) V & This paper & EB3353 \\
\hline C. elegans: pyc-1(gk689405) V & $\begin{array}{l}\text { Caenorhabditis Genetics } \\
\text { Center }\end{array}$ & VC40551 \\
\hline C. elegans: wyls581 IV; pyc-1(gk689405) V & This paper & EB3403 \\
\hline $\begin{array}{l}\text { C. elegans: lect-2(gk864764) II; wyls581 IV; pyc- } \\
\text { 1(gk689405) V }\end{array}$ & This paper & EB3298 \\
\hline C. elegans: gly-12(id47) X & $\begin{array}{l}\text { Caenorhabditis Genetics } \\
\text { Center }\end{array}$ & AS270 \\
\hline C. elegans: dpy6(e14) gly-13(ok712) X & $\begin{array}{l}\text { Caenorhabditis Genetics } \\
\text { Center }\end{array}$ & AS338 \\
\hline C. elegans: gly-14(id48) III & $\begin{array}{l}\text { Caenorhabditis Genetics } \\
\text { Center }\end{array}$ & AS271 \\
\hline $\begin{array}{l}\text { C. elegans: gly-14(id48) III; gly-12(id47) gly- } \\
\text { 13(ok712) X }\end{array}$ & Kind gift of lain Wilson & AS341 \\
\hline C. elegans: gly-20(ok826) V & $\begin{array}{l}\text { Caenorhabditis Genetics } \\
\text { Center }\end{array}$ & RB943 \\
\hline C. elegans: fut-8(ok2558) V & $\begin{array}{l}\text { Caenorhabditis Genetics } \\
\text { Center }\end{array}$ & RB1945 \\
\hline C. elegans: hex-2(ok2985) V & $\begin{array}{l}\text { Caenorhabditis Genetics } \\
\text { Center }\end{array}$ & RB2205 \\
\hline C. elegans: hex-3(gk944651) III & $\begin{array}{l}\text { Caenorhabditis Genetics } \\
\text { Center }\end{array}$ & VC40929 \\
\hline $\begin{array}{l}\text { C. elegans: lect-2(gk864764) II; wyls581 IV; gly- } \\
\text { 12(id47) X }\end{array}$ & This paper & EB3407 \\
\hline $\begin{array}{l}\text { C. elegans: lect-2(gk864764) II; wyls581 IV; } \\
\text { dpy6(e14) gly-13(ok712) X }\end{array}$ & This paper & EB3408 \\
\hline C. elegans: wyls581 IV; gly-20(ok826) V & This paper & EB3410 \\
\hline C. elegans: wyls581 IV; fut-8(ok2558) V & This paper & EB3411 \\
\hline $\begin{array}{l}\text { C. elegans: lect-2(gk864764) II; otls173 III; wyls581 } \\
\text { IV; hex-2(ok2985) V }\end{array}$ & This paper & EB3653 \\
\hline $\begin{array}{l}\text { C. elegans: lect-2(gk864764) II; hex-3(gk944651) III; } \\
\text { wyls581 IV; him-5(ok1896) V }\end{array}$ & This paper & EB3905 \\
\hline $\begin{array}{l}\text { C. elegans: lect-2(gk864764) II; hex-3(gk944651) III; } \\
\text { wyls581 IV; hex-2(ok2985) V }\end{array}$ & This paper & EB3906 \\
\hline $\begin{array}{l}\text { C. elegans: ddls290 lect-2(gk864764) II; gly-14(id48) } \\
\text { III; wyls581 IV }\end{array}$ & This paper & EB3638 \\
\hline $\begin{array}{l}\text { C. elegans: ddls290 lect-2(gk864764) II; wyls581 IV; } \\
\text { gly-12(id47) gly-13(ok712)X }\end{array}$ & This paper & EB3637 \\
\hline $\begin{array}{l}\text { C. elegans: ddls290 lect-2(gk864764) II; gly-14(id48) } \\
\text { III; wyls581 IV; gly-12(id47) gly-13(ok712) X }\end{array}$ & This paper & EB3636 \\
\hline $\begin{array}{l}\text { C. elegans: dzls53 II; gly-14(id48) III; wyls581 IV; } \\
\text { mnr-1(dz213) V; gly-12(id47) gly-13(ok712) X }\end{array}$ & This paper & EB4376 \\
\hline
\end{tabular}




\begin{tabular}{|c|c|c|}
\hline $\begin{array}{l}\text { C. elegans: dzls53 II; gly-14(id48) III; wyls581 IV; } \\
\text { mnr-1(dz213) aman-2(gk248486) V; gly-12(id47) gly- } \\
\text { 13(ok712) X }\end{array}$ & This paper & EB4377 \\
\hline $\begin{array}{l}\text { C. elegans: dzEx1865(Pser-2prom3::kpc-1::GFP); } \\
\text { dzIs53 I }\end{array}$ & This paper & EB3533 \\
\hline $\begin{array}{l}\text { C. elegans: dzEx1865(Pser-2prom3::kpc-1::GFP); } \\
\text { dzls53 II; aman-2(gk248486) V }\end{array}$ & This paper & EB3667 \\
\hline $\begin{array}{l}\text { C. elegans: dma-1(wy1041[dma-1::2XFLAG]) I; } \\
\text { dzls117 II }\end{array}$ & This paper & EB4239 \\
\hline $\begin{array}{l}\text { C. elegans: dma-1(wy1041[dma-1::2XFLAG]) I; } \\
\text { dzIs117 II; him-5(ok1896) V }\end{array}$ & This paper & EB4378 \\
\hline $\begin{array}{l}\text { C. elegans: dma-1(dz294[dma-1(N280Q)::2xFLAG]) } \\
\text { I; dzIs117 II; him-5(ok1896) V }\end{array}$ & This paper & EB4219 \\
\hline $\begin{array}{l}\text { C. elegans: dma-1(dz294[dma-1(N280Q)::2xFLAG]) } \\
\text { I; dzIs117 II; aman-2(gk248486) V }\end{array}$ & This paper & EB4220 \\
\hline $\begin{array}{l}\text { C. elegans: dma-1(dz294[dma-1(N280Q)::2xFLAG]) } \\
\text { I; dzIs117 II; him-5(ok1896) V }\end{array}$ & This paper & EB4221 \\
\hline $\begin{array}{l}\text { C. elegans: dma-1(dz294[dma-1(N280Q)::2xFLAG]) } \\
\text { l; dzls117 lect-2(gk864764) II; aman-2(gk248486) V }\end{array}$ & This paper & EB4222 \\
\hline $\begin{array}{l}\text { C. elegans: dma-1(dz295[dma-1(N168Q, N219Q } \\
\text {,N280Q)::2xFLAG]) I; dzls117 II; him-5(ok1896) V }\end{array}$ & This paper & EB4223 \\
\hline $\begin{array}{l}\text { C. elegans: dma-1(dz295[dma-1(N168Q, N219Q } \\
\text {,N280Q)::2xFLAG]) I; dzls117 II; aman-2(gk248486) } \\
V\end{array}$ & This paper & EB4224 \\
\hline $\begin{array}{l}\text { C. elegans: dma-1(dz295[dma-1(N168Q, N219Q } \\
\text {,N280Q)::2xFLAG]) I; dzls117 II; him-5(ok1896) V }\end{array}$ & This paper & EB4225 \\
\hline $\begin{array}{l}\text { C. elegans: dma-1(dz295[dma-1(N168Q, N219Q } \\
\text {,N280Q)::2xFLAG]) I; dzls117 lect-2(gk864764) II; } \\
\text { aman-2(gk248486) V }\end{array}$ & This paper & EB4226 \\
\hline $\begin{array}{l}\text { C. elegans: dma-1(dz296[dma-1(N280Q; } \\
\text { N386Q)::2xFLAG]) I; dzls117 II; him-5(ok1896) V }\end{array}$ & This paper & EB4227 \\
\hline $\begin{array}{l}\text { C. elegans: dma-1(dz296[dma-1(N280Q; } \\
\text { N386Q)::2xFLAG]) I; dzls117 II; aman-2(gk248486) V }\end{array}$ & This paper & EB4228 \\
\hline $\begin{array}{l}\text { C. elegans: dma-1(dz296[dma-1(N280Q; } \\
\text { N386Q)::2xFLAG]) I; dzIs117 II; him-5(ok1896) V }\end{array}$ & This paper & EB4229 \\
\hline $\begin{array}{l}\text { C. elegans: dma-1(dz296[dma-1(N280Q; } \\
\text { N386Q)::2xFLAG]) I; dzls117 lect-2(gk864764) II; } \\
\text { aman-2(gk248486) V }\end{array}$ & This paper & EB4230 \\
\hline $\begin{array}{l}\text { C. elegans: dma-1(dz297[dma-1(N168Q, N219Q } \\
\text {,N280Q, N386Q)::2xFLAG]) I; dzIs117 II; him- } \\
5(\text { ok1896) V }\end{array}$ & This paper & EB4231 \\
\hline $\begin{array}{l}\text { C. elegans: dma-1(dz297[dma-1(N168Q, N219Q } \\
\text {,N280Q, N386Q)::2xFLAG]) I; dzIs117 II; aman- } \\
2(\text { gk248486) V }\end{array}$ & This paper & EB4232 \\
\hline $\begin{array}{l}\text { C. elegans: dma-1(dz297[dma-1(N168Q, N219Q } \\
\text {,N280Q, N386Q)::2xFLAG]) I; dzIs117 II; him- } \\
\text { 5(ok1896) V }\end{array}$ & This paper & EB4233 \\
\hline $\begin{array}{l}\text { C. elegans: dma-1(dz297[dma-1(N168Q, N219Q } \\
\text {,N280Q, N386Q)::2xFLAG]) I; dzls117 lect- } \\
2(g k 864764) \text { II; aman-2(gk248486) V }\end{array}$ & This paper & EB4234 \\
\hline $\begin{array}{l}\text { C. elegans: dma-1(dz298[dma-1(N386Q)::2xFLAG]) } \\
\text { I; dzIs117 II; him-5(ok1896) V }\end{array}$ & This paper & EB4235 \\
\hline $\begin{array}{l}\text { C. elegans: dma-1(dz298[dma-1(N386Q)::2xFLAG]) } \\
\text { I; dzIs117 II; aman-2(gk248486) V }\end{array}$ & This paper & EB4236 \\
\hline
\end{tabular}




\begin{tabular}{|c|c|c|}
\hline $\begin{array}{l}\text { C. elegans: dma-1(dz298[dma-1(N386Q)::2xFLAG]) } \\
\text { I; dzls117 II; him-5(ok1896) V }\end{array}$ & This paper & EB4237 \\
\hline $\begin{array}{l}\text { C. elegans: dma-1(dz298[dma-1(N386Q)::2xFLAG]) } \\
\text { I; dzls117 lect-2(gk864764) II; aman-2(gk248486) V }\end{array}$ & This paper & EB4238 \\
\hline \multicolumn{3}{|l|}{ Oligonucleotides } \\
\hline $\begin{array}{l}\text { guide RNA for S1: N126 } \\
\text { [TAATACGACTCACTATAGGATAGAGACAATGATC } \\
\text { GCAGTTTTAGAGCTAGAAATAGCAAG] }\end{array}$ & This paper & oMR103 \\
\hline $\begin{array}{l}\text { guide RNA for S2: N219 } \\
\text { [TAATACGACTCACTATAgTTCCAAGTTGACGGAG } \\
\text { TTGGTTTTAGAGCTAGAAATAGCAAG] }\end{array}$ & This paper & oMR122 \\
\hline $\begin{array}{l}\text { guide RNA for S3: N280 } \\
\text { [TAATACGACTCACTATAgTTCGTATTGCAAAATGC } \\
\text { ACGTTTTAGAGCTAGAAATAGCAAG] }\end{array}$ & This paper & oMR123 \\
\hline $\begin{array}{l}\text { guide RNA for S4: N386 } \\
\text { [TAATACGACTCACTATAgAATGTTCAATGAAATCA } \\
\text { GGGTTTTAGAGCTAGAAATAGCAAG] }\end{array}$ & This paper & oMR124 \\
\hline $\begin{array}{l}\text { repair for S1: N126Q } \\
\text { [CGAAGTAAATTTGTAGAAAGATCACTGATAGTAT } \\
\text { TCTGAGAGAGGGACAGGGAGCGGAGAGCTCTAA } \\
\text { GATATGTGAATACTCCAGTTGGAAGAAT] }\end{array}$ & This paper & oMR130 \\
\hline $\begin{array}{l}\text { repair for S2: N219Q } \\
\text { [GTTTCTCAATTGGATGAATTATATTTGAATCATTG } \\
\text { CCAGCTCTCCTCCATCTACTCCCTCGCACTCGAC } \\
\text { CGCATCCCTCAGCTGCGCCAGCTGGGAATCGGA } \\
\text { GGAAATAATCTCAAAATGGTTCCAAC] }\end{array}$ & This paper & oMR131 \\
\hline $\begin{array}{l}\text { repair for S3: N280Q } \\
\text { [CCGAGCAAATTGTGGGAAAGATCTAATTTTGAGA } \\
\text { TCTGCGTATTGCAAAATGCACAAGCTGTGATTTC } \\
\text { TTGAATGGAATTGTGAGACAAGTC] }\end{array}$ & This paper & oMR127 \\
\hline $\begin{array}{l}\text { repair for S4: N386Q } \\
\text { [TTGTCAGGCAAATAAGTCAATTCATTTCCAGAAA } \\
\text { TCTGCAGTGAGATGAGGTGATAATAGCGAGACG } \\
\text { GCAGCTGTACCGGGATGAATTT] }\end{array}$ & This paper & oMR132 \\
\hline $\begin{array}{l}\text { genotype } \$ 1 \text { forward } \\
\text { [GAGTTCTTCGTCTCATCAATTG] }\end{array}$ & This paper & oMR107 \\
\hline $\begin{array}{l}\text { genotype S1 reverse } \\
\text { [GAATAGGATTCCGGTCTAGTCG] }\end{array}$ & This paper & oMR108 \\
\hline $\begin{array}{l}\text { genotype S2, S3 forward } \\
\text { [CTGCGATCATTGTCTCTATCC] }\end{array}$ & This paper & oMR109 \\
\hline $\begin{array}{l}\text { genotype S2 reverse } \\
\text { [CCATCCCAACCATTTTGAGTC] }\end{array}$ & This paper & oMR129 \\
\hline genotype S3 reverse [GGTCCATGACTCCTCGAAA] & This paper & oMR111 \\
\hline $\begin{array}{l}\text { genotype S4 forward } \\
\text { [GCACATGAACAATCCCAAGG] }\end{array}$ & This paper & oMR112 \\
\hline $\begin{array}{l}\text { To clone Pser2prom3::aman-2, Pdpy-7::aman-2, } \\
\text { Pmyo-3::aman-2 forward } \\
\text { [TTCAGGAGGACCCTTGGAGGGTACcATGGGAAA } \\
\text { ACGCAATTTCTATATTATCCTA] }\end{array}$ & This paper & oMR34 \\
\hline $\begin{array}{l}\text { To clone Pser2prom3::aman-2, Pdpy-7::aman-2, } \\
\text { Pmyo-3::aman-2 reverse } \\
\text { [GATATTTCCAGTATTCTTGTATCATTTTAAtCCGG } \\
\text { AACCCGCCTTTGTCTGATCT] }\end{array}$ & This paper & oMR35 \\
\hline
\end{tabular}




\begin{tabular}{|c|c|c|}
\hline $\begin{array}{l}\text { To clone Pser2prom3::aman-2 catalytic dead site } 1 \\
\text { forward [CATTGGTCAATTGCCCCATTCGGTTTATC] }\end{array}$ & This paper & oMR64 \\
\hline $\begin{array}{l}\text { To clone Pser2prom3::aman-2 catalytic dead site } 1 \\
\text { reverse } \\
\text { [GATAAACCGAATGGGGCAATTGACCAATG] }\end{array}$ & This paper & oMR65 \\
\hline $\begin{array}{l}\text { To clone Pser2prom3::aman-2 catalytic dead site } 2 \\
\text { forward [CCACTTGGAGATGCCTTCAGGTACGAC] }\end{array}$ & This paper & oMR66 \\
\hline $\begin{array}{l}\text { To clone Pser2prom3::aman-2 catalytic dead site } 2 \\
\text { reverse [GTCGTACCTGAAGGCATCTCCAAGTGG] }\end{array}$ & This paper & oMR67 \\
\hline \multicolumn{3}{|l|}{ Recombinant DNA } \\
\hline Plasmid: Pser2prom3::aman-2 & $\begin{array}{l}\text { The aman-2 cDNA was } \\
\text { PCR amplified with } \\
\text { Kpnl/Bspel cloning sites } \\
\text { attached and cloned into } \\
\text { Pser2prom3::lect-2. }\end{array}$ & $\mathrm{N} / \mathrm{A}$ \\
\hline Plasmid: Pdpy-7::aman-2 & $\begin{array}{l}\text { The aman-2 cDNA from } \\
\text { Pser2prom3::aman-2 } \\
\text { was cloned into Pdpy- } \\
\text { 7::lect-2 with Kpnl/Bspel. }\end{array}$ & $\mathrm{N} / \mathrm{A}$ \\
\hline Plasmid: Pmyo-3::aman-2 & $\begin{array}{l}\text { The aman-2cDNA from } \\
\text { Pser2prom3::aman-2 } \\
\text { was cloned into Pmyo- } \\
\text { 3::lect-2 with Kpnl/ Bspel. }\end{array}$ & N/A \\
\hline Plasmid: Pser2prom3::aman-2 catalytic dead & $\begin{array}{l}\text { The Pser2prom3::aman-2 } \\
\text { was PCR amplified with } \\
\text { the NEB Q5 site directed } \\
\text { mutagenesis kit. }\end{array}$ & N/A \\
\hline \multicolumn{3}{|l|}{ Endoglycosidases } \\
\hline PNGase F (\#P0704S) & $\begin{array}{l}\text { NEB } \\
\text { https://www.neb.com/pr } \\
\text { oducts/p0704-pngase- } \\
\text { f\#Product\%20Informati } \\
\text { on }\end{array}$ & P0704S \\
\hline Endo H (\#P0702L) & $\begin{array}{l}\text { NEB } \\
\text { https://www.neb.com/pr } \\
\text { oducts/p0702-endo- } \\
\text { h\#Product\%20Informati } \\
\text { on }\end{array}$ & P0702L \\
\hline Endo D (\#P0742S) & $\begin{array}{l}\text { NEB } \\
\text { https://www.neb.com/pr } \\
\text { oducts/p0742-remove- } \\
\text { it-endo- } \\
\text { d\#Product\%20Informati } \\
\text { on }\end{array}$ & P0742S \\
\hline \multicolumn{3}{|l|}{ Antibodies } \\
\hline $\begin{array}{l}\text { Monoclonal primary Anti-GFP in mouse (Roche } \\
\text { 11814460001) }\end{array}$ & $\begin{array}{l}\text { Roche } \\
\text { https://www.sigmaaldrich. } \\
\text { com/US/en/product/roche } \\
\text { /11814460001 }\end{array}$ & 11814460001 \\
\hline $\begin{array}{l}\text { Monoclonal primary Anti-FLAG in mouse (Sigma } \\
\text { F1804) }\end{array}$ & $\begin{array}{l}\text { Sigma } \\
\text { https://www.sigmaaldrich. } \\
\text { com/US/en/product/sigm } \\
\text { a/f1804 }\end{array}$ & F1804 \\
\hline
\end{tabular}




\begin{tabular}{|c|c|c|}
\hline $\begin{array}{l}\text { Polyclonal secondary Anti-mouse HRP (Millipore } \\
\text { AP308P) }\end{array}$ & $\begin{array}{l}\text { Millipore } \\
\text { https://www.emdmillipore. } \\
\text { com/US/en/product/Goat- } \\
\text { Anti-Mouse-IgG- } \\
\text { Antibody-H+L-HRP- } \\
\text { conjugate,MM_NF- } \\
\text { AP308P }\end{array}$ & AP308P \\
\hline \multicolumn{3}{|l|}{ Western Blot reagents } \\
\hline $4-12 \%$ Bis-Tris Gradient Gels & $\begin{array}{l}\text { GenScript } \\
\text { https://www.genscript.co } \\
\text { m/molecule/M00653- } \\
\text { SurePAGE_Bis_Tris_10x } \\
\text { 8_4_12_12_wells.html }\end{array}$ & M00653 \\
\hline Protein A/G agarose beads (sc-2003) & $\begin{array}{l}\text { Santa Cruz } \\
\text { https://www.scbt.com/p/p } \\
\text { rotein-a-g-plus-agarose }\end{array}$ & Sc-2003 \\
\hline \multicolumn{3}{|l|}{ Software and Algorithms } \\
\hline FIJI & https://fiji.sc/ & $\mathrm{N} / \mathrm{A}$ \\
\hline GraphPad PRISM 8 & $\begin{array}{l}\text { https://www.graphpad.co } \\
\text { m/scientific- } \\
\text { software/prism/ }\end{array}$ & $\mathrm{N} / \mathrm{A}$ \\
\hline
\end{tabular}

\section{C. elegans handling}

All strains were maintained using standard methods (Brenner, 1974) and experiments were performed at $20^{\circ} \mathrm{C}$, except where indicated otherwise. Phenotypic analysis was performed in 1-day-old adults, with no more than 4-5 eggs present. For details and a complete list of strains used and generated in this study, see resources table.

\section{Cloning of mutant alleles}

The $d z 261$ allele was obtained from a forward genetic screen for modifiers of the lect-2(gk864764) hypomorphic allele. Using a combination of whole genome sequencing and single nucleotide polymorphism mapping (Minevich et al, 2012), we narrowed down the region to a $5 \mathrm{Mb}$ interval $(11 \mathrm{MB}-16 \mathrm{Mb}$ on chromosome $\mathrm{V}$ (Fig.EV1A). This region contained 7 polymorphisms with predicted functional consequences. We injected seven fosmids in pools and found that only the pool which contained a fosmid covering aman-2 resulted in rescue (Fig.EV1B). In addition, we obtained three nonsense alleles in aman-2 
(gk248486, gk248477, gk619253) from the Million Mutation Project (Thompson et al, 2013) and one deletion allele (tm1078, kind gift from the Mitani lab).

\section{Details of genetic screen and cloning}

The lect-2(gk864764) hypomorphic strain was treated with EMS in accordance with standard chemical mutagenesis protocols (Kutscher \& Shaham, 2014) and F1 progeny were scored for enhancement, suppression, or modification of PVD branching phenotype. A SNP-mapping-WGS (Doitsidou et al, 2016) approach was used to map aman-2(dz261) between $10 \mathrm{Mb}$ and $16 \mathrm{Mb}$ of chromosome $\mathrm{V}$. This region contained seven candidates with nonsense, missense, frameshift or splice site mutations, including one in aman-2. The $d z 261$ mutation was further confirmed by Sanger sequencing of the original isolate, identifying a nonsense mutation W237Opal in the aman-2 locus.

\section{Heterologous rescue of PVD dendrite branching defect}

The aman-2 cDNA was cloned under control of heterologous promoters: hypodermal Pdpy-7 (Gilleard et al, 1997), body wall muscle Pmyo-3 (Okkema et al, 1993), and PVD Pser2prom3 (Tsalik et al, 2003). All constructs were injected at $5 \mathrm{ng} / \mu \mathrm{l}$ into wdls52 II; him-5(ok1896) $V$ together with the Pmyo-2::mCherry marker at $50 \mathrm{ng} / \mu \mathrm{l}$ and pBluescript at $50 \mathrm{ng} / \mathrm{\mu l}$. Males from transgenic lines were then crossed into lect-2(gk864764) II; wyls581 IV; aman-2(gk248477) V and wyls581 IV; mnr-1(dz213) aman-2(gk248486) V.

\section{Cloning constructs and transgenesis}

To assemble tissue specific expression constructs used for heterologous rescue experiments, the aman-2 cDNA clone $y$ k11g705 (kind gift of Yoji Kohara) and cloned under control of the following promoters: PVD ser2prom-3 (Tsalik et al., 2003), hypodermal dpy-7p (Gilleard et al., 1997), body wall muscle myo-3p (Okkema et al., 1993). These constructs were injected at $5 \mathrm{ng} / \mu \mathrm{l}$ together with myo-2p::mCherry as an injection marker at $50 \mathrm{ng} / \mu \mathrm{l}$, and BlueScript as DNA filler. Point mutants in the aman-2 cDNA were introduced by site-specific mutagenesis (NEB Q5 Site-Directed 
Mutagenesis). All plasmids contained the unc-54 3'UTR.

\section{Pharmacology}

Experiments in which the activity of AMAN-2 was blocked pharmacologically were performed with the compound swainsonine (1 mg swainsonine \#16860 vials, Fisher

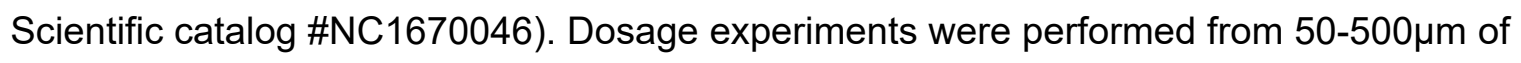
swainsonine in dissolved in agar of NGM plates, with $300 \mu \mathrm{m}$ being sufficient to elicit phenotypes in PVD. After drying for 24 hours, $200 \mu \mathrm{L}$ of OP50 E. coli was seeded onto each plate, and 5 young adult worms were left to self-fertilize and lay eggs. The F1 generations were analyzed, imaged, and quantified. DMSO was used a control in plates not treated with swainsonine.

\section{Molecular Biology}

Immunoprecipitation and Western blot analyses of glycoproteins were performed using standard SDS-PAGE methods. Whole C. elegans lysates were prepared in RIPA buffer and sonicated in a Biorupter benchtop waterbath sonicator for 15 minutes. Lysates were treated with 1 unit at temperatures as indicated in NEB protocols (linked in Key Resources Table) endoglycosidases PNGase F, Endo $H$, or Endo D where specified. Overnight immunoprecipitation of lysates with anti-GFP antibody prior to SDSPAGE was performed for proteins with low expression levels (DMA-1::GFP and KPC$1:: G F P)$

\section{Immunoprecipitation and Western blot Analysis}

Five full plates of DMA-1::GFP and KPC-1::GFP tagged worms were washed in RIPA buffer pH7.0 and lysed for 15 minutes in a Biorupter water bath used previously published methods of whole worm protein extraction (Li \& Zinovyeva, 2020). Post lysis, $20 \mathrm{uL}$ of Protein A/G Plus Agarose beads (Santa Cruz sc-2003) and 1 uL of anti-GFP antibody (Roche 11814460001) were used to pull down DMA-1::GFP and KPC-1::GFP overnight at 4C. Ten gravid adult SAX-7::GFP::FLAG animals and twenty LECT- 
2::mNG::FLAG animals were sufficient to see robust expression post Western Blot. These samples were boiled and loaded directly into the gels. Gradient gels $(4-12 \%$ GenScript) were used in all experiments. For all anti-FLAG blots, a concentration of 1:800 anti-Flag (Sigma F1804) and 1:5000 anti-mouse HRP (Millipore AP308P) were used. For all anti-GFP blots, a concentration of 1:500 anti-GFP (Roche 11814460001) and 1:5000 anti-mouse HRP (Millipore AP308P) were used.

\section{CRISPR/Cas9 mediated gene editing}

CRISPR-Cas9 constructs were designed and dpy-10 co-crispr protocol followed as previously described (Dickinson \& Goldstein, 2016) to make single point mutations of predicted $\mathrm{N}$-glycan attachment Asparagine residues. Predicted sites were identified using NetNGlyc 1.0 Server (Gupta \& Brunak, 2002). A battery of guideRNAs were designed to direct Cas9 cuts near sites of interest, and homologous repair template oligomers were designed to mutate Asparagine residues to Glutamine. All plasmids were delivered via microinjection in the gonads of animals. Strains with combinations of mutated sites were generated by sequential injections and/or multiple simultaneous edits. Note, that all edits were made in strains with the C-terminus of DMA-1 already tagged with a 2XFLAG immunotag before the PDZ binding domain (Dong et al., 2016). Strains EB4219 through EB4238 in the Key Resources Table were obtained using these methods.

\section{Imaging}

Fluorescent images were captured in live C. elegans using a Plan-Apochromat $40 \times / 1.4$ or $63 x / 1.4$ objective on a Zeiss Axioimager Z1 Apotome. Worms were immobilized using $1 \mathrm{mM}$ Levamisole and $Z$ stacks were collected. Maximum intensity projections were used for further analysis and tracing of dendrites. For quantification of branching, 1-day-old adults were mounted onto slides and immobilized with $1 \mathrm{mM}$ Levamisole. In both cases of capturing images and counting, and counting live on the 
microscope, the number of "Ts" (secondary and tertiary branches), "Os," (self-avoidance defects), and/or quaternary branches within $100 \mu \mathrm{m}$ of the primary branch anterior to the cell body were quantified.

\section{Quantification and statistical analysis}

Statistical comparisons were conducted on Prism 8 GraphPad Software using MannWhitney, Kruskal-Wallis, Z-, or two-sided ANOVA tests as appropriate. Statistical significance is indicated as ns, not significant; ${ }^{*} \mathrm{p} \leq 0.05 ;{ }^{* *} \mathrm{p} \leq 0.01 ;{ }^{* * *} \mathrm{p} \leq 0.001$ and ${ }^{* * * *} \mathrm{p} \leq 0.0001$. This study includes no data deposited in external repositories. 


\section{EXPANDED VIEW FIGURES}

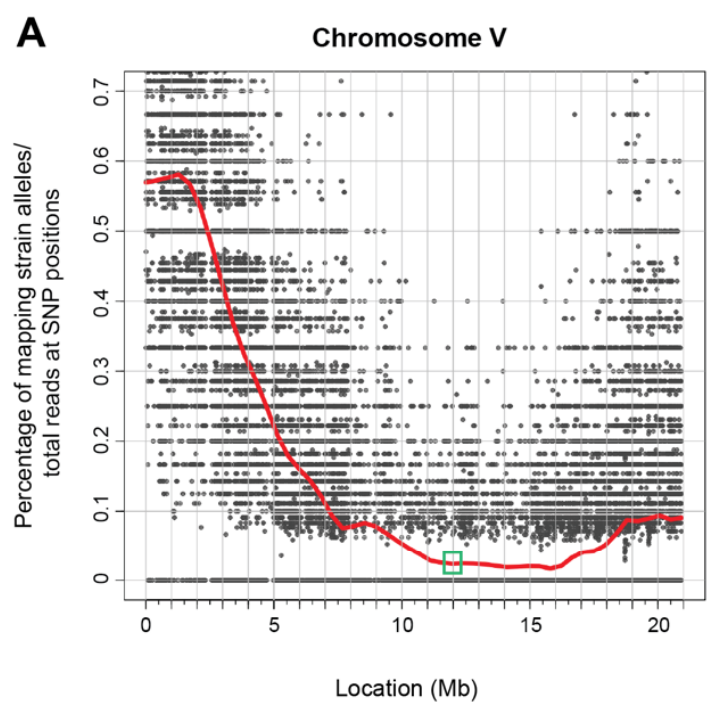

\begin{tabular}{llc}
\hline B & \multicolumn{2}{c}{$\begin{array}{c}\text { Fosmid rescue of PVD defects in } \\
\text { lect-2(hyp); dz261 mutants }\end{array}$} \\
\hline gene/transcript ID & fosmid number & rescued lines \\
\hline $\begin{array}{c}\text { pyc-1 } \\
\text { aman-2 }\end{array}$ & WRM0640aD10 & \multirow{2}{*}{ WRM0617dH10 } \\
\hline mpst-7 & WRM0624aG04 & \multirow{2}{*}{$0 / 3$} \\
srh-24 & WRM0624cC12 & \\
\hline T26E4.4 & WRM0638dB04 & \\
sqst-4 & WRM0628aH05 & $0 / 5$ \\
F59A1.11 & WRM0637bA11 & \\
\hline
\end{tabular}

$\mathbf{D}$ Number of secondaries $\left(2^{\circ}\right)$

\begin{tabular}{ccc}
\hline $\mathbf{C}$ & \multicolumn{2}{c}{$\begin{array}{c}\text { Novel alleles isolated } \\
\text { in lect-2(hyp) modifier screen }\end{array}$} \\
\hline allele & gene & mutation \\
\hline$d z 252$ & $m n r-1$ & R459H \\
$d z 253$ & sax-7 & loss of splice donor site exon 4 \\
$d z 254$ & $k p c-1$ & L535F \\
$d z 261$ & aman-2 & W237Opal \\
\hline
\end{tabular}

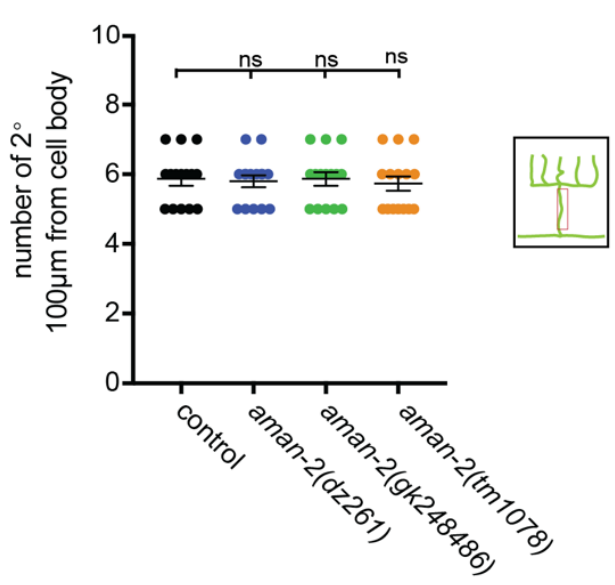

Figure EV1 Results of modifier screen and identification of AMAN-2/Golgi Alphamannosidase II

(A) Graph of single nucleotide polymorphism (SNP) results after whole genome sequencing of the $d z 261$ allele (Doitsidou et al., 2016). Axes are denoted above. The green box shows the genomic position of aman-2 (11.92-11.93 Mb on Chromosome V).

(B) Table showing the candidate genes selected and tested as a result of the SNP data in (A). Pools of fosmids covering the regions of indicated transcripts were injected into the lect-2(hyp) dz261 double mutant. Only the pool containing a fosmid including aman-2 showed rescue. pyc-1 was eliminated because a null allele ( $g k 689405)$ failed to enhance the lect-2(hyp).

(C) Table summarizing different additional alleles isolated in the lect-2(gk864764) hypomorph modifier screen and their molecular lesions.

(D) Quantification of the number of secondary branches (indicated in schematic) in various aman-2 mutant alleles and in wild type control animals. Data are represented as mean \pm SEM. Statistical significance was calculated using the Kruskal-Wallis test and is indicated ( $n s=$ no significance). $n=15$ for all genotypes. 
A

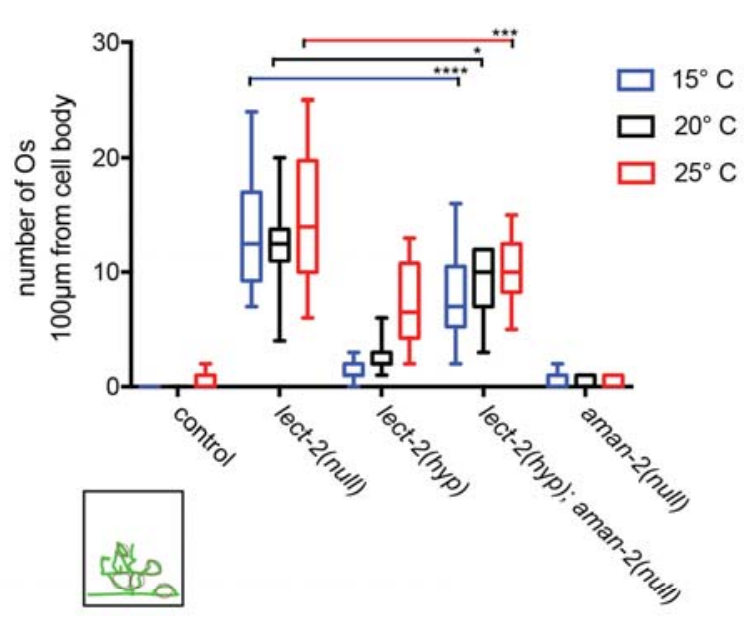

C

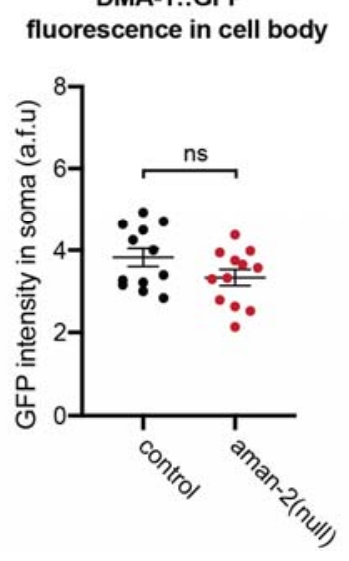

B

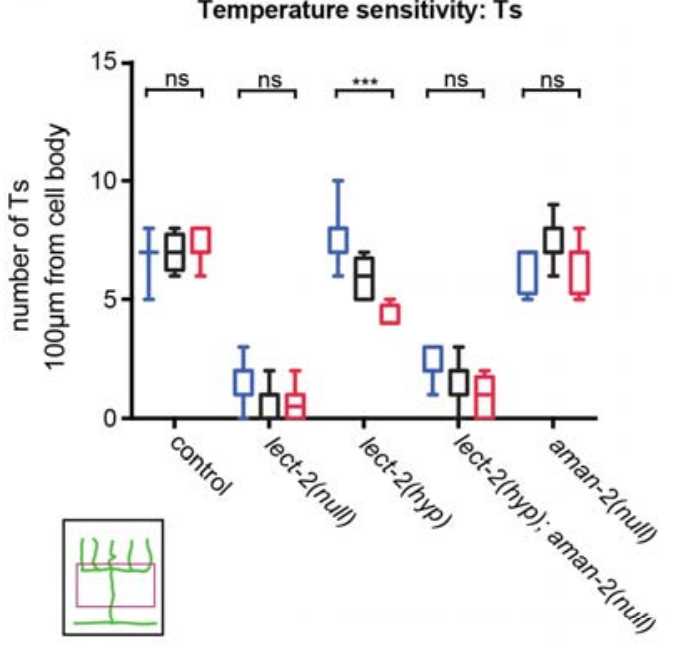

E fluorescence in primary branch

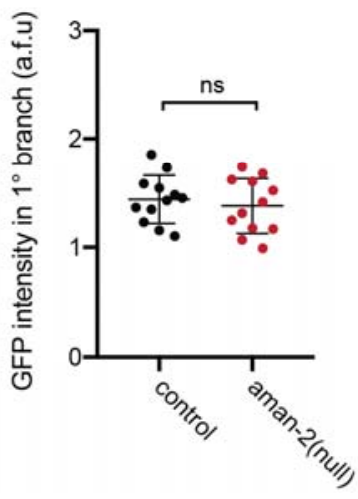
DMA-1::GFP
puncta in tertiary branch

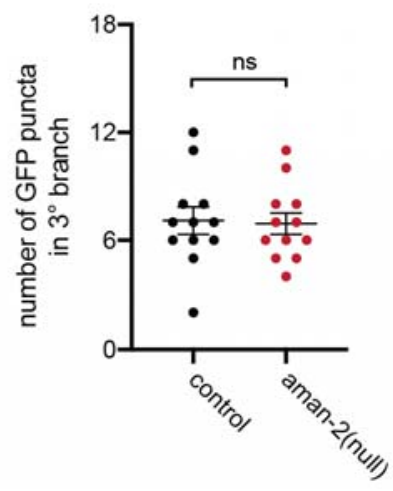

Figure EV2 The requirement of AMAN-2 in PVD may be specific rather than global

(A) Quantification of "Os" (overlapping branches as shown in schematic) of denoted genotypes at different temperatures. Data are represented as mean \pm SEM.

Statistical comparisons were performed using two-way ANOVA tests. Statistical significance is indicated $\left({ }^{*} p \leq 0.05,{ }^{* * *} p \leq 0.001,{ }^{* * * \star} p \leq 0.0001\right.$, ns $=$ not significant). $n$ $>11$ for all groups.

(B) Quantification of "Ts" of denoted genotypes at different temperatures. Data are represented as mean \pm SEM. Statistical comparisons were performed using two-way ANOVA tests. Statistical significance is indicated $\left({ }^{* * *} p \leq 0.001, n s=\right.$ not significant). $n$ $>11$ for all groups.

(C) Quantification of DMA-1::GFP fluorescence in control and aman-2(gk248486) animals. GFP intensity is quantified in arbitrary fluorescent units by dividing the fluorescent area of the soma by the background. Data are represented as mean \pm SEM. Statistical comparisons were performed using the Mann-Whitney test. (ns=not significant). $n=12$.

(D) Quantification of DMA-1::GFP fluorescence in control and aman-2(gk248486) animals. GFP intensity is quantified in arbitrary fluorescent units by measuring the fluorescence along the primary dendrite, up to $60 \mu \mathrm{m}$ anterior from the cell body. Data are represented as mean \pm SEM. Statistical comparisons were performed using the Mann-Whitney test. ( $n s=$ not significant). $n=12$. 
bioRxiv preprint doi: https://doi.org/10.1101/2021.10.11.464022; this version posted October 13, 2021. The copyright holder for this preprint (which was not certified by peer review) is the author/funder. All rights reserved. No reuse allowed without permission.

(E) Quantification of DMA-1::GFP fluorescent puncta in control and aman-2(gk248486) animals. Puncta in the tertiary branches $60 \mu \mathrm{m}$ anterior to the cell body were counted. Data are represented as mean \pm SEM. Statistical comparisons were performed using the Mann-Whitney test. (ns=not significant). $n=12$. 
A

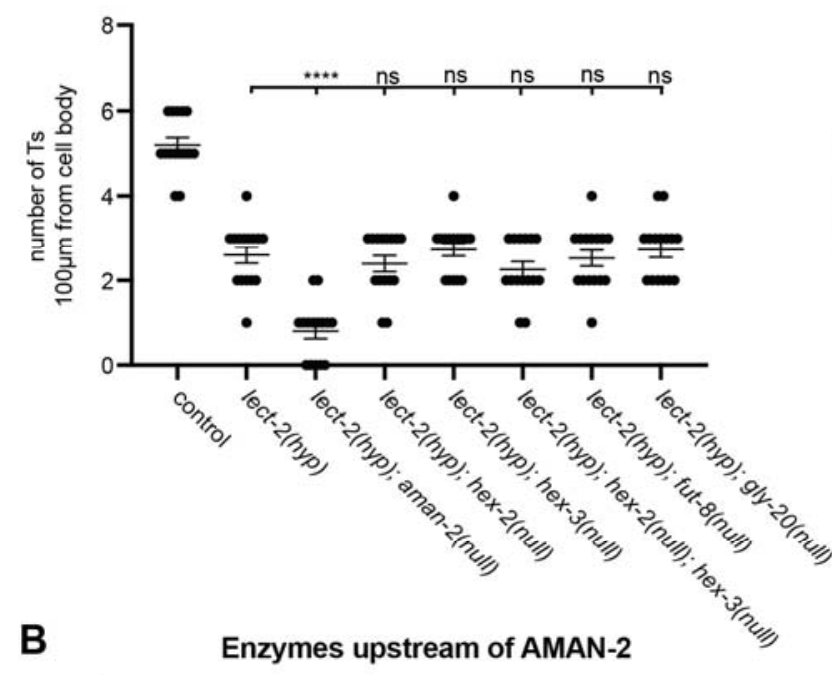

C Number of quarternaries $\left(4^{\circ}\right)$

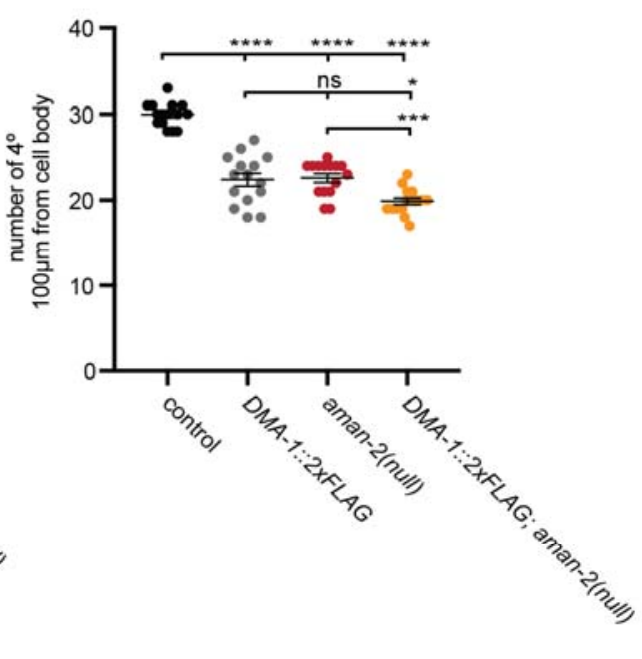

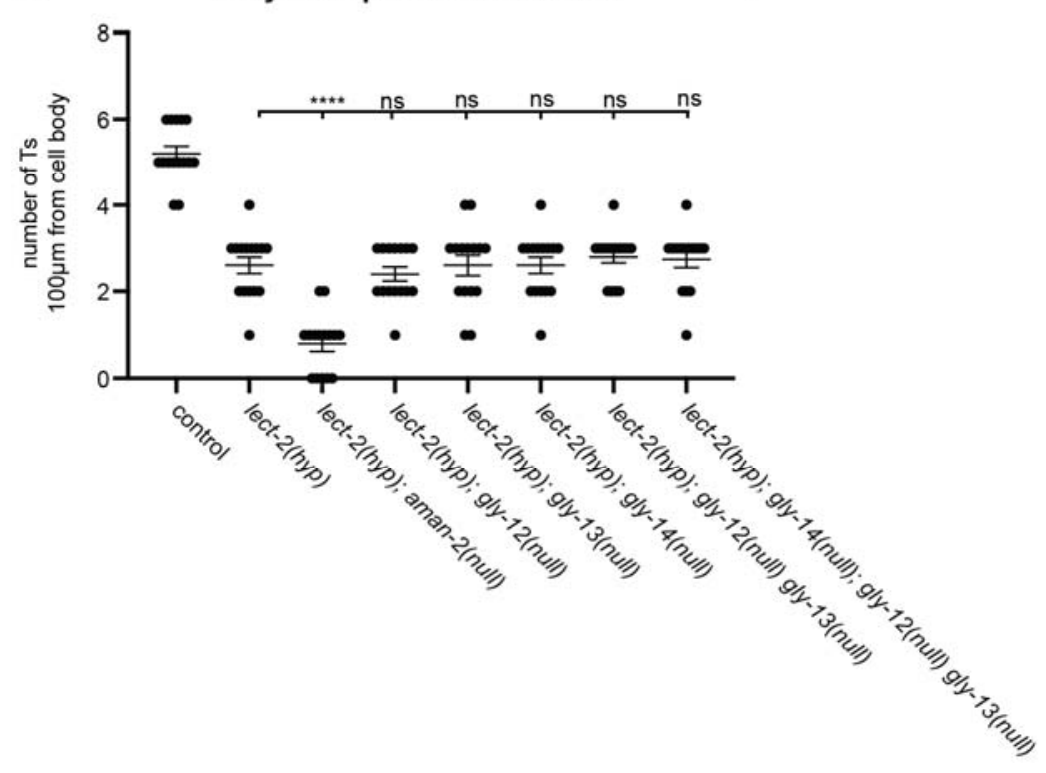

Figure EV3 Quantification of branching in $\mathbf{N}$-glycosylation pathway mutants.

(A) Quantification of the number of "Ts" in wild type controls, lect-2(gk864764) hypomorphs, and lect-2(gk864764) in combination with mutants of MGAT1 orthologs. See strain list for alleles. Data are represented as mean \pm SEM. Statistical significance was calculated using the Kruskal-Wallis test and is indicated $\left(^{* * * *} p \leq\right.$ $0.0001 ; n s=$ not significant). $n=15$ for all genotypes.

(B) Quantification of the number of "Ts" in wild type controls, lect-2(gk864764) hypomorphs, and lect-2(gk864764) in combination with mutants of enzymes acting downstream of aman-2. See strain list for alleles. Data are represented as mean \pm SEM. Statistical significance was calculated using the Kruskal-Wallis test and is indicated $\left(^{* * * *} p \leq 0.0001 ; n s=\right.$ not significant). $n=15$ for all genotypes.

(C) Quantification of the number of quaternary branches in wild type control animals, DMA-1::2XFLAG (denoted as DMA-1 wildtype in Figure 4), and in combination with aman-2(gk248486). In the DMA-1::2XFLAG (wy1041) background, there is a baseline decrease in the number of branches, possibly due to the insertion of the tag (Dong et al., 2016). While equivalent to the phenotype of aman-2(gk248486), 
combining the two backgrounds results in a further decrease in quaternary branches, providing and additional example of how hypomorphic alleles in the Menorin pathway can be enhanced by loss aman-2. Data are represented as mean \pm SEM. Statistical significance was calculated using the Kruskal-Wallis test and is indicated ( ${ }^{*} p \leq 0.05$, $\left.{ }^{* * *} p \leq 0.001,{ }^{* * *} p \leq 0.0001\right) . n=15$ for all genotypes. 
A

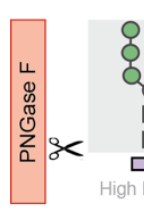

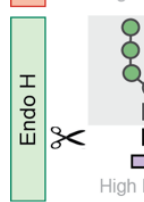
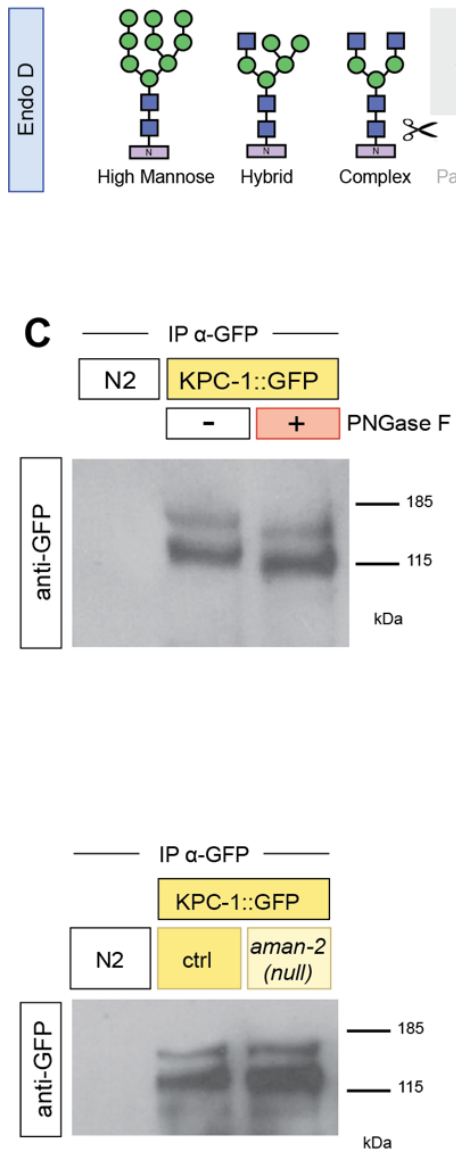
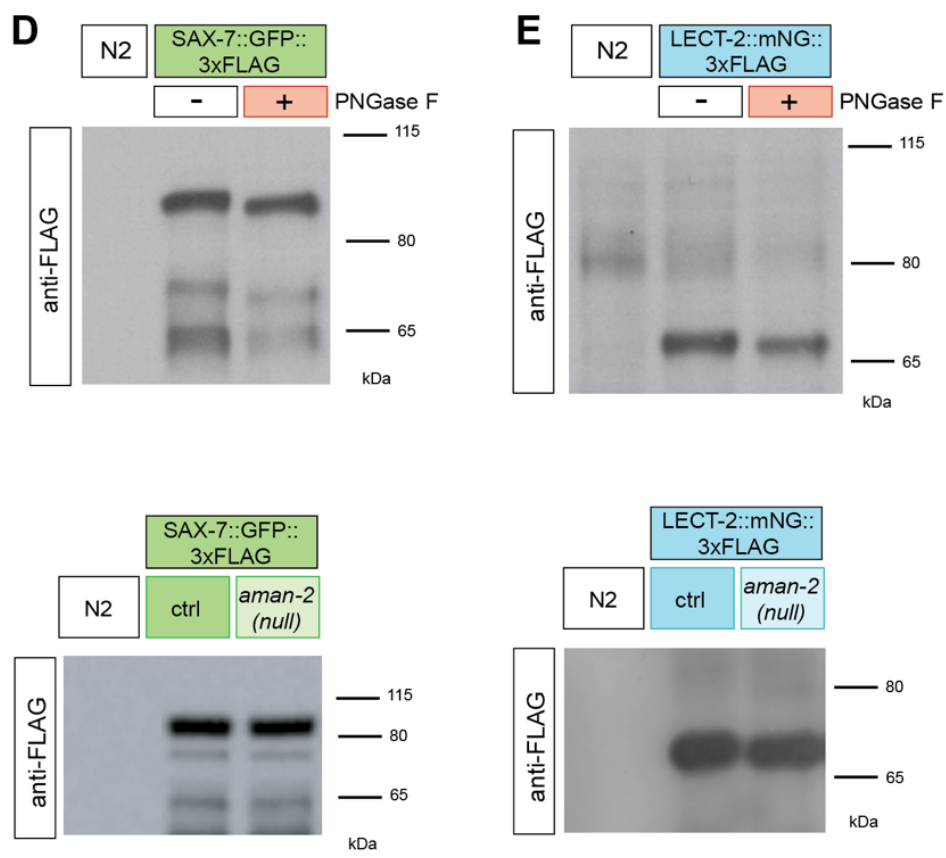

Figure EV4 Members of the Menorin pathway are $\mathrm{N}$-glycosylated.

(A) Schematic of endoglycosidase activity on $\mathrm{N}$-glycan chains. The gray shading represents parts of the chain that are cleaved by each respective endoglycosidase. Glycan residues are consistent with Figure $2 \mathrm{~A}$, and colors of endoglycosidases correspond to Figure 3E,G.

(B) Western blot against GFP in C. elegans lysate DMA-1::GFP (qy/s369), after precipitating with anti-GFP antibody. Control indicates an otherwise wild type background as opposed to an aman-2(gk248486) background. The red boxed $+F$ indicates that the lysate is treated with the PNGase F glycosidase, while the green boxed $+\mathrm{D}$ corresponds to the Endo $\mathrm{D}$ glycosidase, which cleaves paucimannose type $\mathrm{N}$-glycans. Size shifts indicate that some paucimannose structures are present on DMA-1 (left), and that the aman-2 mutant results in the loss of paucimannose structures on DMA-1 (right). Ladder is marked in kilodaltons $(\mathrm{kDa})$. 
(C) Western blot against GFP in C. elegans lysate expressing no transgenes (N2) and expressing KPC-1::GFP (dzEx1865), after precipitating with anti-GFP antibody. The red boxed plus sign indicates that the lysate is treated with the PNGase $F$ glycosidase. The downwards size shift reveals that $N$-glycan structures are present on KPC-1. In the bottom blot, control indicates an otherwise wild type background as opposed to an aman-2(gk248486) background. No size shift is observed.

(D) Western blot against FLAG in C. elegans lysate expressing no transgenes (N2) and expressing SAX-7::GFP::3XFLAG (ds/s290). Robust expression precludes the need for immunoprecipitation. The red boxed plus sign indicates that the lysate is treated with the PNGase $\mathrm{F}$ glycosidase. The downwards size shift reveals that $N$-glycan structures are present on SAX-7. In the bottom blot, control indicates an otherwise wild type background as opposed to an aman-2(gk248486) background. No size shift is observed. The FLAG epitope contains no $N$-glycosylation sites.

(E) Western blot against FLAG in C. elegans lysate expressing no transgenes (N2) and expressing endogenous LECT-2::mNeonGreen::3XFLAG (dz249). Robust expression precludes the need for immunoprecipitation. The red boxed plus sign indicates that the lysate is treated with the PNGase $F$ glycosidase. The small downwards size shift reveals that $N$-glycan structures are present on LECT-2. In the bottom blot, control indicates an otherwise wild type background as opposed to an aman-2(gk248486) background. No size shift is observed. 


\section{REFERENCES}

Albeg A, Smith CJ, Chatzigeorgiou M, Feitelson DG, Hall DH, Schafer WR, Miller DM, 3rd, Treinin M (2011) C. elegans multi-dendritic sensory neurons: morphology and function. Mol Cell Neurosci 46: 308-317

Apweiler R, Hermjakob H, Sharon N (1999) On the frequency of protein glycosylation, as deduced from analysis of the SWISS-PROT database. Biochim Biophys Acta 1473: 4-8

Brenner S (1974) The genetics of Caenorhabditis elegans. Genetics 77: 71-94

Bülow HE, Hobert O (2006) The Molecular Diversity of Glycosaminoglycans Shapes Animal Development. Ann Rev Cell Dev Biol 22: 375-407

Chang IJ, He M, Lam CT (2018) Congenital disorders of glycosylation. Ann Transl Med 6: 477

Chen S, Spence Andrew M, Schachter H (2003) Isolation of null alleles of the Caenorhabditis elegans gly-12, gly-13 and gly-14 genes, all of which encode UDP-

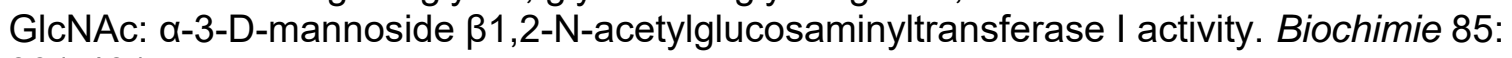
391-401

Chen S, Zhou S, Sarkar M, Spence AM, Schachter H (1999) Expression of three Caenorhabditis elegans $\mathrm{N}$-acetylglucosaminyltransferase I genes during development. J Biol Chem 274: 288-297

Dennis JW, Nabi IR, Demetriou M (2009) Metabolism, cell surface organization, and disease. Cell 139: 1229-1241

Diaz-Balzac CA, Rahman M, Lazaro-Pena MI, Martin Hernandez LA, Salzberg Y, Aguirre-Chen C, Kaprielian Z, Bülow HE (2016) Muscle- and Skin-Derived Cues Jointly Orchestrate Patterning of Somatosensory Dendrites. Curr Biol 26: 2379-2387

Dickinson DJ, Goldstein B (2016) CRISPR-Based Methods for Caenorhabditis elegans Genome Engineering. Genetics 202: 885-901

Doitsidou M, Jarriault S, Poole RJ (2016) Next-Generation Sequencing-Based Approaches for Mutation Mapping and Identification in Caenorhabditis elegans. Genetics 204: 451-474

Dong X, Chiu H, Park YJ, Zou W, Zou Y, Ozkan E, Chang C, Shen K (2016) Precise regulation of the guidance receptor DMA-1 by KPC-1/Furin instructs dendritic branching decisions. Elife 5

Dong X, Liu OW, Howell AS, Shen K (2013) An extracellular adhesion molecule complex patterns dendritic branching and morphogenesis. Cell 155: 296-307

Dong X, Shen K, Bülow HE (2015) Intrinsic and extrinsic mechanisms of dendritic morphogenesis. Annu Rev Physiol 77: 271-300 
Feng Z, Zhao Y, Li T, Nie W, Yang X, Wang X, Wu J, Liao J, Zou Y (2020) CATP-8/P5A ATPase Regulates ER Processing of the DMA-1 Receptor for Dendritic Branching. Cell Rep 32: 108101

Fogel Al, Li Y, Giza J, Wang Q, Lam TT, Modis Y, Biederer T (2010) N-glycosylation at the SynCAM (synaptic cell adhesion molecule) immunoglobulin interface modulates synaptic adhesion. J Biol Chem 285: 34864-34874

Freeze HH (2006) Genetic defects in the human glycome. Nat Rev Genet 7: 537-551

Gasser B, Saloheimo M, Rinas U, Dragosits M, Rodriguez-Carmona E, Baumann K, Giuliani M, Parrilli E, Branduardi P, Lang C et al (2008) Protein folding and conformational stress in microbial cells producing recombinant proteins: a host comparative overview. Microb Cell Fact 7: 11

Gilleard JS, Barry JD, Johnstone IL (1997) cis regulatory requirements for hypodermal cell-specific expression of the Caenorhabditis elegans cuticle collagen gene dpy-7. $\mathrm{Mol}$ Cell Biol 17: 2301-2311

Gupta R, Brunak S (2002) Prediction of glycosylation across the human proteome and the correlation to protein function. Pac Symp Biocomput: 310-322

Holt CE, Dickson BJ (2005) Sugar codes for axons? Neuron 46: 169-172

Inberg S, Meledin A, Kravtsov V, losilevskii Y, Oren-Suissa M, Podbilewicz B (2019) Lessons from Worm Dendritic Patterning. Annu Rev Neurosci 42: 365-383

loffe E, Stanley P (1994) Mice lacking N-acetylglucosaminyltransferase I activity die at mid-gestation, revealing an essential role for complex or hybrid $\mathrm{N}$-linked carbohydrates.

Jaeken J, Peanne R (2017) What is new in CDG? J Inherit Metab Dis 40: 569-586

Jan YN, Jan LY (2010) Branching out: mechanisms of dendritic arborization. Nat Rev Neurosci 11: 316-328

Kaji H, Kamiie J, Kawakami H, Kido K, Yamauchi Y, Shinkawa T, Taoka M, Takahashi $\mathrm{N}$, Isobe $\mathrm{T}$ (2007) Proteomics reveals $\mathrm{N}$-linked glycoprotein diversity in Caenorhabditis elegans and suggests an atypical translocation mechanism for integral membrane proteins. Mol Cell Proteomics 6: 2100-2109

Kutscher LM, Shaham S (2014) Forward and reverse mutagenesis in C. elegans. WormBook: 1-26

Labasque M, Hivert B, Nogales-Gadea G, Querol L, Illa I, Faivre-Sarrailh C (2014) Specific contactin N-glycans are implicated in neurofascin binding and autoimmune targeting in peripheral neuropathies. J Biol Chem 289: 7907-7918

Lefebvre JL (2021) Molecular mechanisms that mediate dendrite morphogenesis. In: Current Topics in Developmental Biology, Academic Press: 
Li L, Zinovyeva AY (2020) Protein Extract Preparation and Co-immunoprecipitation from Caenorhabditis elegans. $J$ Vis Exp

Lu H, Wang SS, Wang WL, Zhang L, Zhao BY (2014) Effect of swainsonine in Oxytropis kansuensis on Golgi alpha-mannosidase II expression in the brain tissues of SpragueDawley rats. J Agric Food Chem 62: 7407-7412

Masu M (2016) Proteoglycans and axon guidance: a new relationship between old partners. J Neurochem 139 Suppl 2: 58-75

Medina-Cano D, Ucuncu E, Nguyen LS, Nicouleau M, Lipecka J, Bizot JC, Thiel C, Foulquier F, Lefort N, Faivre-Sarrailh C et al (2018) High N-glycan multiplicity is critical for neuronal adhesion and sensitizes the developing cerebellum to $\mathrm{N}$-glycosylation defect. Elife 7

Metzler M, Gertz A, Sarkar M, Schachter H, Schrader JW, Marth JD (1994) Complex asparagine-linked oligosaccharides are required for morphogenic events during postimplantation development. EMBO J 13: 2056-2065

Minevich G, Park DS, Blankenberg D, Poole RJ, Hobert O (2012) CloudMap: a cloudbased pipeline for analysis of mutant genome sequences. Genetics 192: 1249-1269

Mire E, Hocine M, Bazellieres E, Jungas T, Davy A, Chauvet S, Mann F (2018) Developmental Upregulation of Ephrin-B1 Silences Sema3C/Neuropilin-1 Signaling during Post-crossing Navigation of Corpus Callosum Axons. Curr Biol 28: 1768-1782 e1764

Moloney DJ, Panin VM, Johnston SH, Chen J, Shao L, Wilson R, Wang Y, Stanley P, Irvine KD, Haltiwanger RS et al (2000) Fringe is a glycosyltransferase that modifies Notch [see comments]. Nature 406: 369-375

Moremen KW (2002) Golgi a-mannosidase II deficiency in vertebrate systems: implications for asparagine-linked oligosaccharide processing in mammals. Biochimica et Biophysica Acta 1573: 225-235

Ng BG, Freeze HH (2018) Perspectives on Glycosylation and Its Congenital Disorders. Trends Genet 34: 466-476

Okkema PG, Harrison SW, Plunger V, Aryana A, Fire A (1993) Sequence requirements for myosin gene expression and regulation in Caenorhabditis elegans. Genetics 135: 385-404

Oren-Suissa M, Hall DH, Treinin M, Shemer G, Podbilewicz B (2010) The fusogen EFF1 controls sculpting of mechanosensory dendrites. Science 328: 1285-1288

Paschinger K, Hackl M, Gutternigg M, Kretschmer-Lubich D, Stemmer U, Jantsch V, Lochnit G, Wilson IB (2006) A deletion in the golgi alpha-mannosidase II gene of Caenorhabditis elegans results in unexpected non-wild-type N-glycan structures. J Biol Chem 281: 28265-28277 
Paschinger K, Yan S, Wilson IBH (2019) N-glycomic Complexity in Anatomical Simplicity: Caenorhabditis elegans as a Non-model Nematode? Front Mol Biosci 6: 9

Poulain FE, Yost HJ (2015) Heparan sulfate proteoglycans: a sugar code for vertebrate development? Development 142: 3456-3467

Salzberg Y, Coleman AJ, Celestrin K, Cohen-Berkman M, Biederer T, Henis-Korenblit S, Bülow HE (2017) Reduced Insulin/Insulin-Like Growth Factor Receptor Signaling Mitigates Defective Dendrite Morphogenesis in Mutants of the ER Stress Sensor IRE-1. PLoS Genet 13: e1006579

Salzberg Y, Diaz-Balzac CA, Ramirez-Suarez NJ, Attreed M, Tecle E, Desbois M, Kaprielian Z, Bülow HE (2013) Skin-Derived Cues Control Arborization of Sensory Dendrites in Caenorhabditis elegans. Cell 155: 308-320

Salzberg Y, Ramirez-Suarez NJ, Bülow HE (2014) The proprotein convertase KPC$1 /$ furin controls branching and self-avoidance of sensory dendrites in Caenorhabditis elegans. PLoS Genet 10: e1004657

Schroeder NE, Androwski RJ, Rashid A, Lee H, Lee J, Barr MM (2013) Dauer-specific dendrite arborization in C. elegans is regulated by KPC-1/Furin. Curr Biol 23: 1527-1535

Sekine SU, Haraguchi S, Chao K, Kato T, Luo L, Miura M, Chihara T (2013) Meigo governs dendrite targeting specificity by modulating ephrin level and $\mathrm{N}$-glycosylation. Nat Neurosci 16: 683-691

Shah N, Kuntz DA, Rose DR (2008) Golgi alpha-mannosidase II cleaves two sugars sequentially in the same catalytic site. Proc Natl Acad Sci U S A 105: 9570-9575

Smith CJ, O'Brien T, Chatzigeorgiou M, Spencer WC, Feingold-Link E, Husson SJ, Hori S, Mitani S, Gottschalk A, Schafer WR et al (2013) Sensory Neuron Fates Are Distinguished by a Transcriptional Switch that Regulates Dendrite Branch Stabilization. Neuron 79: 266-280

Smith CJ, Watson JD, Spencer WC, O'Brien T, Cha B, Albeg A, Treinin M, Miller DM, 3rd (2010) Time-lapse imaging and cell-specific expression profiling reveal dynamic branching and molecular determinants of a multi-dendritic nociceptor in C. elegans. Dev Biol 345: 18-33

Stanley P, Taniguchi N, Aebi M (2015) N-Glycans. In: Essentials of Glycobiology, rd, Varki A., Cummings R.D., Esko J.D., Stanley P., Hart G.W., Aebi M., Darvill A.G., Kinoshita T., Packer N.H. et al (eds.) pp. 99-111. Cold Spring Harbor (NY)

Sundararajan L, Stern J, Miller DM, 3rd (2019) Mechanisms that regulate morphogenesis of a highly branched neuron in C. elegans. Dev Biol 451: 53-67

Tang LT, Diaz-Balzac CA, Rahman M, Ramirez-Suarez NJ, Salzberg Y, Lazaro-Pena MI, Bülow HE (2019) TIAM-1/GEF can shape somatosensory dendrites independently of its GEF activity by regulating F-actin localization. Elife 8 
Thompson O, Edgley M, Strasbourger P, Flibotte S, Ewing B, Adair R, Au V, Chaudhry I, Fernando L, Hutter $\mathrm{H}$ et al (2013) The million mutation project: a new approach to genetics in Caenorhabditis elegans. Genome Res 23: 1749-1762

Tsalik EL, Niacaris T, Wenick AS, Pau K, Avery L, Hobert O (2003) LIM homeobox gene-dependent expression of biogenic amine receptors in restricted regions of the $C$. elegans nervous system. Dev Biol 263: 81-102

Vabulas RM, Raychaudhuri S, Hayer-Hartl M, Hartl FU (2010) Protein folding in the cytoplasm and the heat shock response. Cold Spring Harb Perspect Biol 2: a004390

Wei X, Howell AS, Dong X, Taylor CA, Cooper RC, Zhang J, Zou W, Sherwood DR, Shen $\mathrm{K}$ (2015) The unfolded protein response is required for dendrite morphogenesis. Elife 4: e06963

Zou W, Shen A, Dong X, Tugizova M, Xiang YK, Shen K (2016) A multi-protein receptorligand complex underlies combinatorial dendrite guidance choices in C. elegans. Elife 5 